\title{
Efficacy and safety of various primary treatment strategies for very early and early hepatocellular carcinoma: a network meta-analysis
}

Sha Yang ${ }^{1,4,5,6,7,8,9}$, Huapeng Lin² and Jianning Song ${ }^{3 *}$

\begin{abstract}
Background: Several treatments are available for treatment of early and very early-stage Hepatocellular Carcinoma, also known as small Hepatocellular Carcinoma (SHCC). However, there is no consensus with regards to the efficacies of these methods. We aimed at identifying the most effective initial treatment strategy for SHCC through Bayesian network meta-analyses.

Methods: Studies published between January, 2010, and February, 2021 were searched in EMBASE, Cochrane Library, PubMed and Web of science databases, and conference proceedings for trials. The included studies reported the survival outcomes of very early and early Hepatocellular Carcinoma patients subjected to radiofrequency ablation (RFA), microwave ablation (MWA), surgical resection (SR), transarterial chemoembolization (TACE), percutaneous ethanol injection (PEI), minimally invasive liver surgery (MIS), stereotactic body radiotherapy (SBRT) and cryoablation (CA). Then, data were extracted from studies that met the inclusion criteria. Patient survival data were retrieved from the published Kaplan-Meier curves and pooled. A Bayesian random-effects model was used to combine direct and indirect evidence.
\end{abstract}

Results: A total of 2058 articles were retrieved and screened, from which 45 studies assessing the efficacies of 8 different treatments in 11,364 patients were selected. The included studies had high methodological quality. Recurrence free survival* (progression/recurrence/relapse/disease/tumor-free survival were combined and redefined as

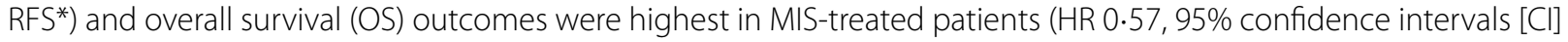
0.38-0.85; HR 0.48,95\% Cl 0.36-0.64, respectively), followed by SR-treated patients (HR 0.60, 95\% Cl 0.50-0.74; HR 0.62, $95 \% \mathrm{Cl} 0.55-0.72$, respectively). TACE was highly efficacious (58.9\%) at decreasing the rates of major complications. Similar findings were obtained through sensitivity analysis, and in most of the prognostic subgroups.

Conclusions: MIS and SR exhibited the highest clinical efficacies, however, they were associated with higher rates of complications. Ablation is effective in small tumors, whereas SBRT is a relatively promising treatment option for SHCC. More well-designed, large-scale randomized controlled trials should be performed to validate our findings.

Keywords: Network meta-analysis, Efficacy, Safety, Treatments, Very early and early-stage, Hepatocellular carcinoma

*Correspondence: jianningsong123@163.com

${ }^{3}$ Department of General Surgery, Guiqian International General Hospital, 1 Dongfeng Dadao, Wudang District, Guiyang, Guizhou 550018, People's Republic of China

Full list of author information is available at the end of the article

\section{Introduction}

Globally, hepatocellular carcinoma (HCC) is the sixth most prevalent tumor and the fourth leading cause of cancer-related deaths [1]. Due to the increase in original author(s) and the source, provide a link to the Creative Commons licence, and indicate if changes were made. The images or other third party material in this article are included in the article's Creative Commons licence, unless indicated otherwise in a credit line to the material. If material is not included in the article's Creative Commons licence and your intended use is not permitted by statutory regulation or exceeds the permitted use, you will need to obtain permission directly from the copyright holder. To view a copy of this licence, visit http://creativecommons.org/licenses/by/4.0/. The Creative Commons Public Domain Dedication waiver (http://creativecommons.org/publicdomain/zero/1.0/) applies to the data made available in this article, unless otherwise stated in a credit line to the data. 
HCC-related mortality, studies are evaluating optimal therapeutic options for this cancer [2, 3]. Cancer surveillance has resulted in early tumor detection, thereby improving the treatment outcomes for very early or early stage HCC, also known as small HCC (SHCC).

The most common therapeutic strategies for SHCC include surgery (such as liver transplantation or surgical resection (SR)), ablation (such as radiofrequency ablation (RFA)), microwave ablation (MWA), cryotherapy ablation (CRA), percutaneous ethanol injection (PEI), non-catheter based therapies, such as stereotactic body radiotherapy (SBRT) and catheter based embolic therapies such as transarterial chemoembolization (TACE). Liver transplantation is the most effective treatment option for SHCC (up to $75 \%$ to $92 \%$-year survival rate) [4]. However, liver transplantation is limited by high costs of the procedure and organ shortage [5]. The European Association for the Study of the Liver (EASL) [6] and American Association for the Study of Liver Diseases (AASLD) [7] recommend surgical resection as the firstline treatment option for SHCC. However, ablation is an effective alternative for patients that are not eligible for surgery. The recently developed minimally invasive liver surgery (MIS) strategy is a safe and effective approach for liver resection [8-10]. Compared to traditional surgery, MIS has a significant short-term efficacy advantage and a similar long-term efficacy [11]. However, the choice of MIS or traditional surgery is challenging. The possibility of complete tumor resection at the early stages has led to the development of several treatment options, including RFA, MWA, PEI and CRA [12-14].

Ablation induces the necrosis of neoplastic cells by modifying the local temperature. This strategy is associated with several advantages, including minimal invasiveness, high safety, cost-effectiveness, and reproducibility. RFA is the most common ablative technique and, in selected patients, it has been shown to exhibit comparable efficacies to surgery. It is an effective replacement therapy for SHCC [15]. In recent years, various ablation methods, such as MWA and CRA have been widely used [16-18]. MWA is a local ablation modality [19] that uses a similar technology as radiofrequency ablation. However, MWA is characterized by higher thermal efficiencies and it requires less ablation time. Compared to RFA, MWA is less susceptible to large vessels that are adjacent (the heat sink effect) to the tumor and is more effective for larger tumors (3-4 $\mathrm{cm}$ in size) [20-22]. In addition, CRA has a comparable efficacy to RFA. Occasionally, CRA is used in high-resource settings [23-25]. When tumor nodules are near large intrahepatic blood vessels or bile ducts, PEI is the preferred treatment method to avoid thermal potential damage by RFA or MWA to these organs [26]. SBRT [27] is an emerging local modality with potent local control rates of $91 \%$ for tumors less than $5 \mathrm{~cm}$ and $74 \%$ for tumors $\geq 5 \mathrm{~cm}$ in size [28]. Compared to best supportive care, TACE is associated with significantly longer overall survival outcomes, [29]. TACE involves intravenous infusions of cytotoxic chemotherapeutic agents. The delivery of embolization particles into the feeding artery of tumors leads to ischemic necrosis of the tumor [30]. Although TACE has a high efficacy, assessment of its effectiveness is challenging. This is because TACE refers to a wide variety of interventions with variable end-points [31].

Therefore, there is no consensus on optimal treatment options for very early or early-stage HCC. In cases where large clinical trials with multiple comparator arms are not available, bayesian network meta-analysis can be used to compare different treatment methods to identify the most effective approach [32]. A random effects network meta-analysis was conducted to compare the efficacies and safety of the primary therapeutic options of SHCC, thereby establishing an optimal treatment for very early or early-stage HCC. Similar studies have been conducted. However, this study included the latest treatments and latest studies. In addition, HR, which is the most reliable effect indicator in survival analyses, relative to $R R$ and $\mathrm{OR}$, was used in comparisons.

\section{Methods}

\section{Search strategy}

All procedures in this meta-analysis were performed in accordance with PRISMA (Preferred Reporting Items for Systematic Reviews and Meta-Analyses) guidelines [33]. Relevant studies published between January 2010 and February 2021 were searched in EMBASE, PubMed, Cochrane Library, Web of science, and conference proceedings. Clinical management of hepatocellular carcinoma has improved in the past 10 years, therefore, relevant studies published from 2010 were included in this study. Searches were conducted using various combinations of Medical Subject Headings (MeSH) and non-MeSH terms. Manual searches were conducted for relevant studies identified from the bibliographies of retrieved articles.

\section{Eligibility criteria}

Eligibility criteria included the study population, intervention, comparison, outcome, and study design (PICOS) [34]. i. The study population comprised very early and early HCC (defined as single nodule $<5 \mathrm{~cm}$ in diameter or up to 3 nodules with the diameter of each nodule being $<3 \mathrm{~cm}$ ) patients. ii. Studies that compared at least 2 intervention techniques, including: RFA, MWA, SR (surgical resection or liver transplantation), TACE, PEI, MIS, SBRT, or CRA. iii. Studies reporting on various 
outcomes, including OS, RFS, PFS, DFS, TFS or major complication rates and iv. Studies that used RCTs or Non-RCTs study designs.

The exclusion criteria were: i. Case reports, letters to the editor, editorials and reviews were excluded; ii. Studies that focused on large $\mathrm{HCC}$, intrahepatic recurrent small HCC, small HCC with extrahepatic metastases or vascular invasions, as well as those that focused on Child-Pugh classification of $\mathrm{C}$ or above; iii. Studies that did not report the relevant outcomes, and iv. Studies whose reported data were replicated in already included studies were excluded.

\section{Study selection and data extraction}

Duplicates were excluded and titles as well as abstracts of the retrieved articles independently screened by two investigators (SY and HPL) using Endnote 7X (Clarivate Analytics; Philadelphia, PA, USA) to determine if they met the inclusion criteria. Full texts of the selected articles were reviewed to determine if they were eligible for inclusion in the analysis. Two authors (SY and JNS) extracted and summarized the data from included studies, including first author names, publication dates, study settings, study designs, mean duration of follow-up, general characteristics, disease characteristics, OS, RFS, DFS and major complication rates. Any disagreements were resolved by consultations with senior authors.

\section{Analysis of methodological qualities of the included studies}

The quality of non-randomized trials was independently evaluated by two investigators using the Newcastle Ottawa Scale [35]. Each study was assigned a maximum of nine stars (six or more stars were considered high quality). The quality of RCTs was determined using the Cochrane' s Risk of Bias Tool for randomized trials, which comprises seven specified domains [36]. Then, RCTs were classified into three categories: low risk, high risk, and having some concerns. Two reviewers (SY and HPL) independently assessed the quality of the included studies. Disagreements were settled by discussion or by consulting a third reviewer.

\section{Statistical analysis}

In this meta-analysis, RFS, PFS, DFS and TFS were combined and redefined as RFS*. DFS was the time from randomization to tumor recurrence or death. PFS was the time between randomization and death or progression (Time to progression is a related, less-preferred end point wherein deaths without progression are censored observations rather than being counted as events) [37]. TFS was the time from randomization to metastasis or recurrence [38]. These terms are not synonyms, but can sometimes represent the same outcome. OS was the time from randomization to the time of all-cause death [39].

Network meta-analysis (NMA) was performed using natural $\log$ transformations of Hazard ratios (HRs) and their 95\% confidence intervals (CIs) to estimate standard errors (SEs), which consider the number and time of events. Hazard ratios (HRs) with 95\% CI were used to determine effect sizes for OS, RFS and DFS. Odds ratios (ORs) with 95\% CI were calculated to determine the effect sizes of major complication rates.

A network-node plot of comparisons was generated to indicate the number of trials that formed direct comparisons between treatment groups. RFA was used as the common parameter for comparisons in order to include all trials within 1 framework. It was assumed that efficacy would not vary based on dosages or schemes. Results were validated using "gemtc" (version $0.8-8$ ) in R (version 4.0.3) and JAGS (version 4.3.0) softwares with identical parameter settings. A random-effects consistency model was used for each outcome measure. Three independent Markov chains were established for running 100000 interactions with 10000 burn-in samples and 10 thinning rates. The process was conducted to obtain a posterior distribution. Model convergence of iterations was evaluated and visualized using trace plots and Brooks-Gelman-Rubin diagnostics. Global inconsistencies were not present, therefore, NMA was performed following the consistency framework [40]. Node-splitting models were used to assess local consistency, and to test whether the results from direct and indirect comparisons were consistent within treatment loops [41]. Statistical heterogeneity and overall network consistency were determined using Q test and statistic inconsistency index (I2). An $\mathrm{I}^{2}$ value $>50 \%$ indicated a significant level of heterogeneity, therefore, sensitivity analyses were conducted by omitting one study at a time to identify heterogeneity sources [42]. Multivariate data were directly extracted from studies. Univariate HR data were extracted if multivariate data were not available. For studies that did not report HR values, the Engauge Digitizer software (version 4.1, M Mitchell) was used to extract data from Kaplan-Meier plots.

\section{Results}

\section{Study characteristics}

A total of 2058 potentially relevant articles were identified from database searches. Then, after removal of duplicates at the initial stage of title and abstract reviews, 1208 articles were excluded because they did not meet the inclusion criteria. Full-texts for 259 articles were retrieved for detailed reviews and assessments. Notably, a total of 214 records were excluded, and 45 articles [20,43-85] involving 11,364 patients were included in 
the final analysis. All included studies reported on overall survival outcomes for patients. Of the 45 included studies, 10 were RCTS while 35 were non-randomized intervention studies (Fig. 1). Two trials were three-arm studies, one comparing SR, TACE, and RFA, the other comparing RFA, MIS and SR, whereas the other trials were two-arm trials. Study characteristics of the RCTs and non-randomized studies are presented in Tables 1 and 2.

The included studies showed a high methodological quality. Analysis using the Cochrane Collaboration tool showed a low risk of bias for the 10 randomized trials. The 35 non-randomized studies were of high quality ( $\geq 7 / 9$ points on the Newcastle-Ottawa scale). Details on quality assessments of randomized and non-randomized studies are presented in Additional file 1: Fig. S1 and Table 2, respectively. A comparison-adjusted funnel plot for the eight therapies network was generated to determine the publication bias. There was no evidence of asymmetry (Additional file 2: Fig. S2).

\section{Network meta-analysis}

The NMA of interventional techniques for very early or early-stage HCC was conducted using the R-software

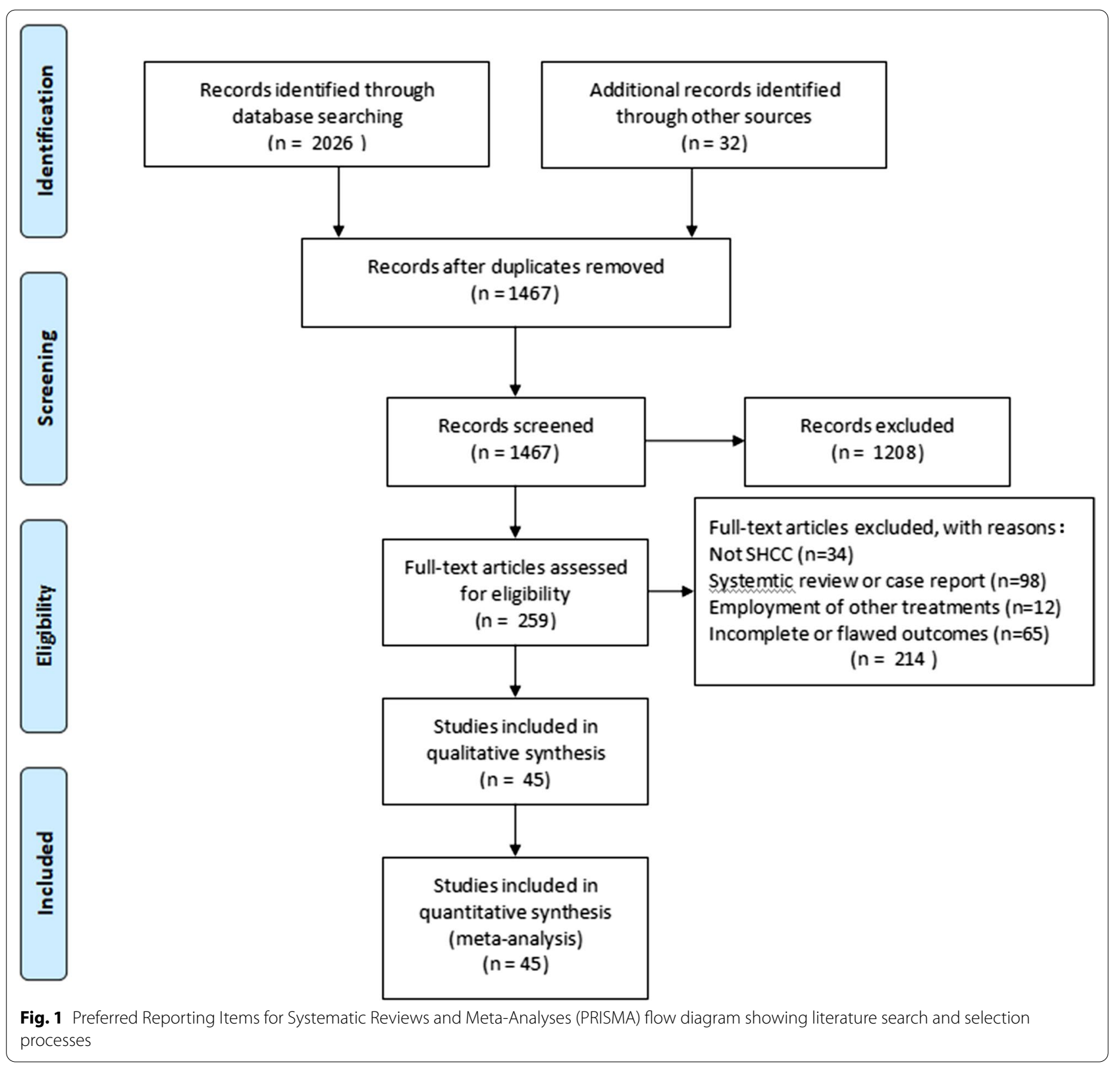




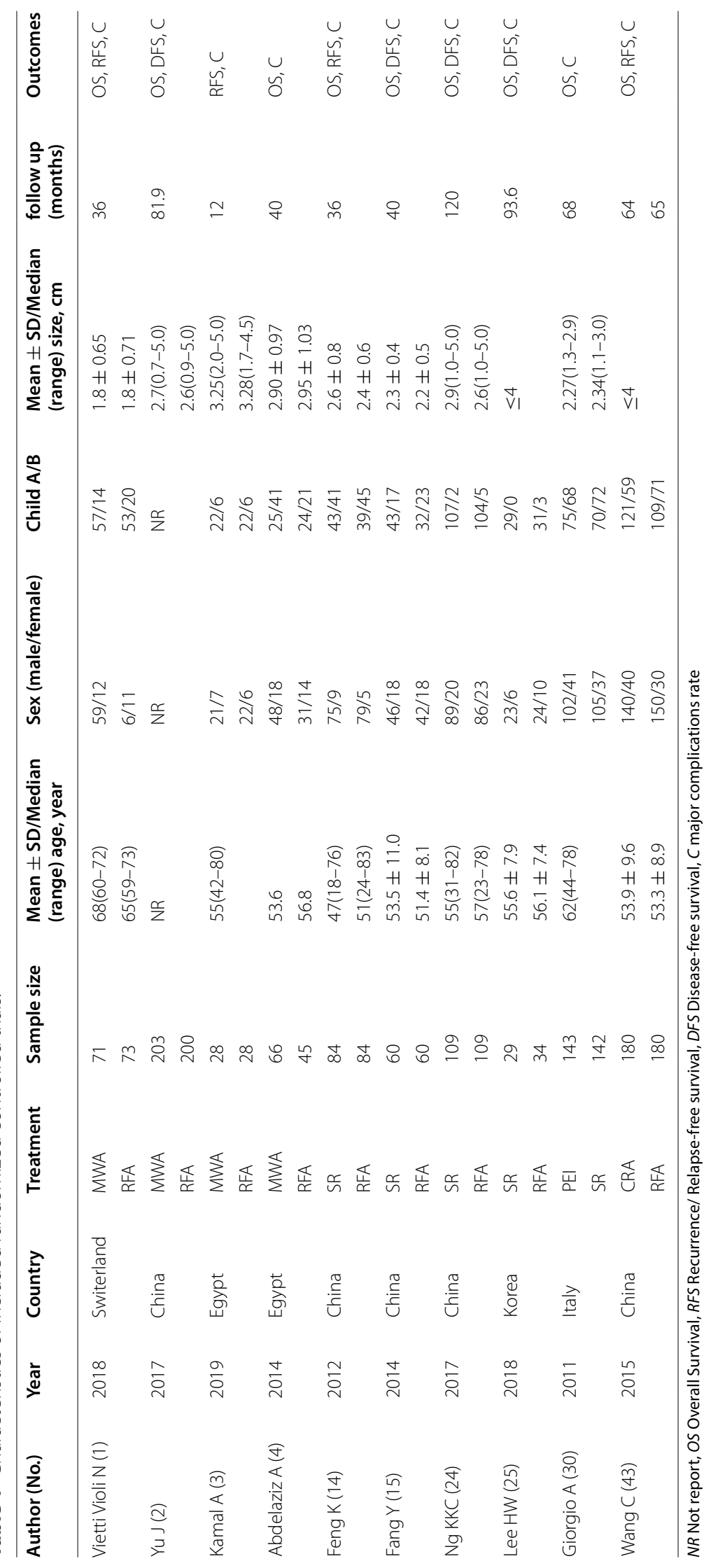




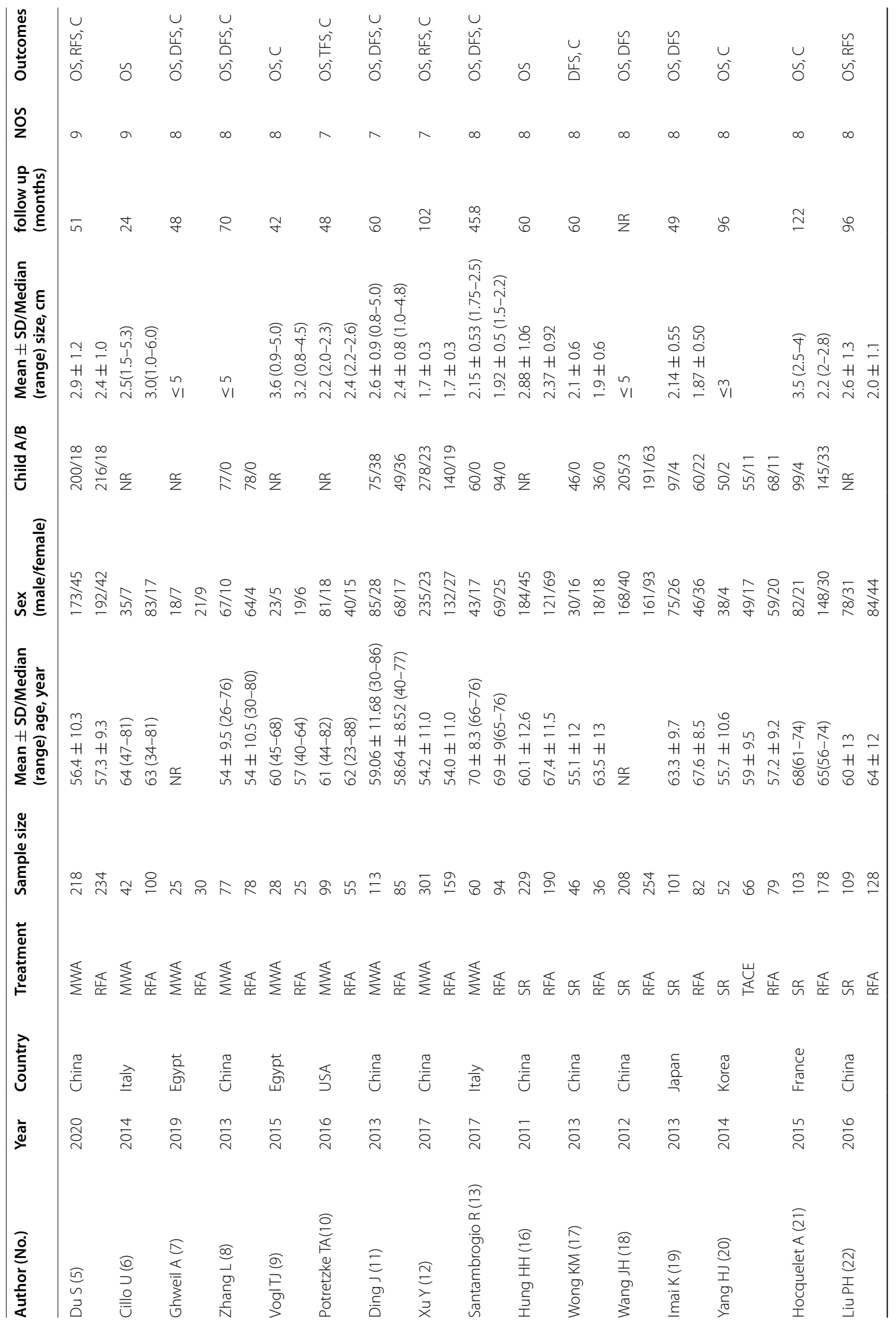




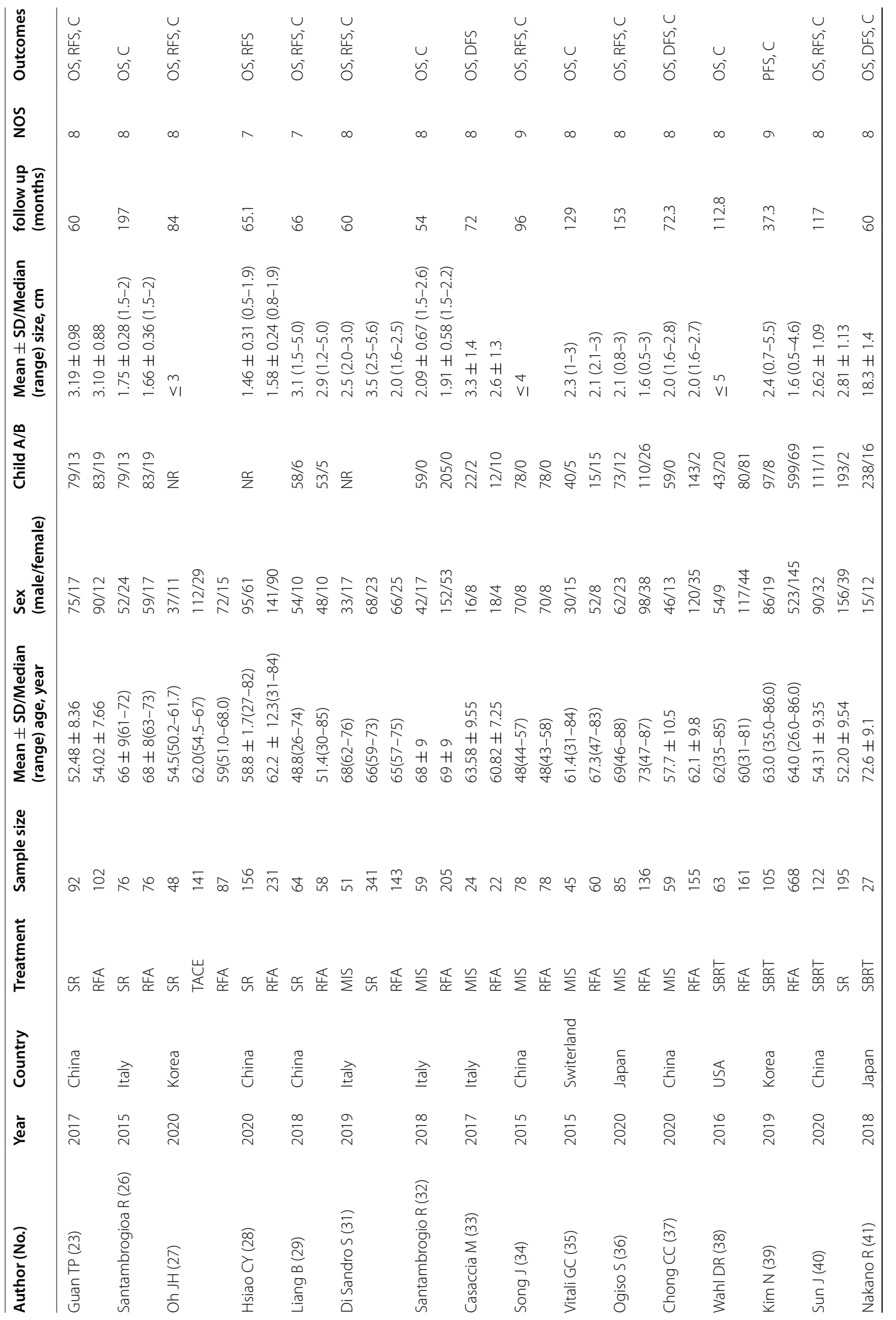




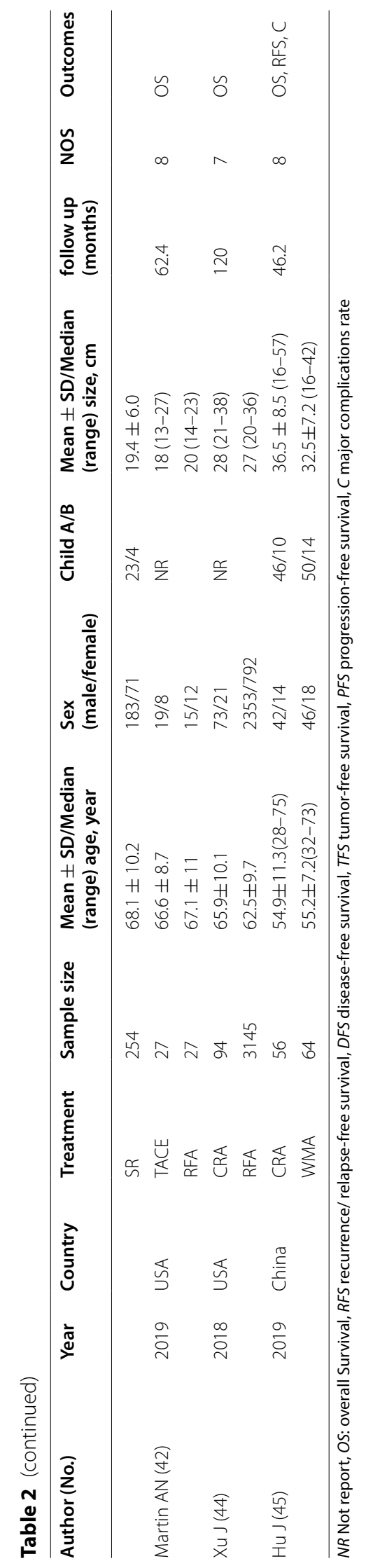


(Fig. 2). The results are presented in the following subsections.

\section{Survival analysis}

OS was reported in 43 trials. The HR and the corresponding $95 \%$ CI of OS were calculated after different treatments. Pooling of HRs for OS revealed a significant advantage for surgery, including SR and MIS, compared to RFA in network meta-analysis (HR 0.60, 95\% CI 0.50-0.74 and HR 0.57, 95\% CI 0.38-0.85, respectively). Pooling of HRs for OS showed a statistically significant advantage for SR, compared to MWA (HR 0.63, 95\% CI 0.48-0.85), TACE (HR 0.42, 95\% CI 0.20-0.86) and RFA (HR 0.60, 95\% CI 0.50-0.74). Pooling of HRs for OS showed a statistically significant advantage for MIS compared to MWA (HR 0.60, 95\% CI 0.38-0.94), TACE (HR 0.39 , 95\% CI 0.18-0.88) and RFA (HR 0.57, 95\% CI 0.380.85). Analysis of OS for patients subjected to ablative electrochemical therapies and non-ablative treatment revealed a high efficacy for MWA, PEI, CRA and SBRT, while the effectiveness of TACE was low, relative to that of RFA. However, differences in OS outcomes after treatment with these therapeutic approaches were not significant. Compared to SR, MIS was associated with better OS outcomes (HR 0.95, 95\% CI 0.60-1.5), however differences were not significant (Fig. 3).

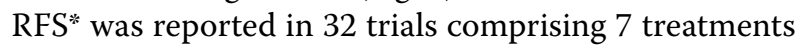
in addition to PEI. SR and MIS had a HR of 0.62 (95\% CI $0.55-0.72)$ and 0.48 (95\% CI 0.36-0.64), respectively, indicating a significant advantage compared to RFA. It was established that SBRT and CRA had better efficacies, whereas TACE was associated with poor RFS*, compared to RFA, however, the differences were not significant. Notably, RFA and MWA exhibited the same RFS. Pooling of HRs for RFS* revealed a significant advantage for SR, compared to MWA (HR 0.61, 95\% CI 0.48-0.76) and TACE (HR 0.31, 95\% CI 0.18-0.52). In addition, pooling of HRs for RFS revealed a statistically significant advantage for MIS, compared to MWA (HR 0.46, 95\% CI 0.330.65), TACE (HR 0.23, 95\% CI 0.13-0.43) and CRA (HR 0.55, 95\% CI 0.34-0.91). All other treatments exhibited significant advantages, relative to TACE (Fig. 4).

Bayesian network meta-analysis indicated that SR (RR 2.70, 95\% CI 1.70-4.30; RR 2.42, 95\% CI 1.23-4.74, respectively) was significantly associated with more severe complications, compared to RFA- and MWAassociated complications. Moreover, TACE (RR 0.14, 95\% CI $0.03-0.60$ ) and SBRT (RR 0.23, 95\% CI 0.08-0.67) were associated with significantly less severe complications, compared to TACE. Furthermore, pooled RR revealed a significant advantage for TACE, compared to MWA (RR 4.78, 95\% CI 1.06-21.47) (Fig. 5).

\section{Consistency analysis}

Adaptation simulation with 10,000 iterations was used for development of the final model for all three outcome parameters. Initial simulation results from MCMC analysis were excluded from the model. The thinning factor was maintained, and the number of chains was set at 4 . The adequacy of convergence for Gelman Rubin diagnostics approached 1 for all outcome parameters. The developed model for model diagnostics is presented in Additional file 3: Fig. S3. Analysis of global inconsistency did not reveal a significant shift in DIC (difference $<5$ ) between the consistency and inconsistency models, implying that the data was consistent. Based on empirical data, node splitting analysis did not show any local inconsistency (Additional file 16: Table S1).

\section{Ranking of treatments}

According to the probability of being the optimal intervention based on associated OS values, each treatment was ranked at each of the possible eight positions (Fig. 6). Rank probability test indicated that MIS had the highest probability of being the optimal intervention (1 with $51.3 \%)$, SR was ranked second, SBRT was third, followed by PEI and CRA, MWA, while RFA was sixth. Notably, TACE was ranked as the worst possible intervention. Analyses of effectiveness according to increasing RFS* revealed consistent results as the results for overall survival outcomes (Fig. 7). MIS had a $89.9 \%$ probability of being the most optimal intervention, SR was ranked second, SBRT was third, CRA was fourth, followed by RFA and MWA, while TACE was the worst possible intervention. MIS and SR had the highest cumulative probabilities of improving OS and RFS outcomes, indicating that MIS and SR were the most effective treatments, compared to the other six interventions. TACE (58.9\%) was ranked the most effective intervention in reduction of severe complication rates, SBRT was ranked second, followed by CRA, RFA, MWA, MIS and PEI, respectively, with SR being the worst possible intervention for reducing severe complications (Fig. 8).

\section{Subgroup analysis results}

Subgroup analyses were performed based on tumor sizes (HCCs $\leq 3 \mathrm{~cm}$ and $\leq 5 \mathrm{~cm}$ ) and study designs (RCT and Non-RCT) with RFS as the endpoint. Moreover, subgroup analyses were conducted according to tumor sizes (HCCs $\leq 3 \mathrm{~cm}$ and $\leq 5 \mathrm{~cm}$ ) and study designs (RCT and Non-RCT) with OS as the endpoint. Studies that reported on OS outcomes were assigned into $\leq 3 \mathrm{~cm}(10$ studies) and $\leq 5 \mathrm{~cm}$ (20 studies) subgroups. Pooled data showed significant benefits for SR, compared to RFA (HR: 0.59; 95\% CI $0.43-0.85$ or WMA (HR: 0.61 ; $95 \%$ CI 


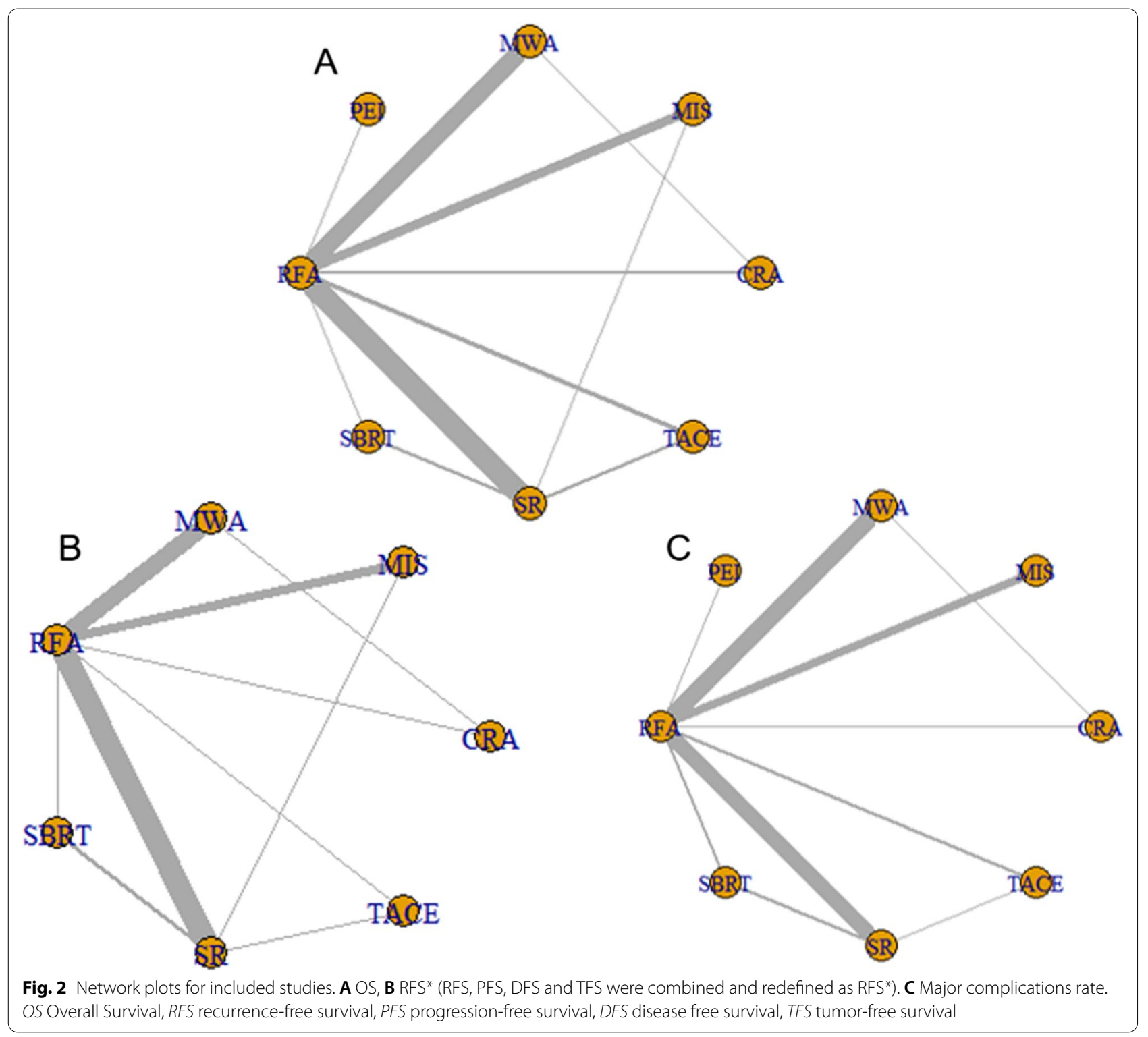

0.41-0.95) for HCC $\leq 5 \mathrm{~cm}$ (Additional file 4: Fig. S4). In addition, MIS exhibited a high efficacy for SR, compared to RFA (HR: $0.44 ; 95 \%$ CI 0.23-0.86) and MWA (HR: 0.46; 95\% CI 0.23-0.93). However, SR and MIS did not exhibit a significant efficacy compared to RFA in patients with $\mathrm{HCC} \leq 3 \mathrm{~cm}$ (Additional file 5: Fig. S5). RCTs provide high-level evidence using the most reliable methods in evaluating the most effective endpoints [86]. Rank orders for these treatments in relation to better OS were: $\mathrm{SR}>\mathrm{CRA}>\mathrm{RFA}>\mathrm{WMA}>\mathrm{PEI}$ in the RCTs subgroup (Additional file 6: Fig. S6). However, differences among these treatments were not significant. Notably, there was a potential selection bias in relatively low-level evidence in non-RCTs. MIS showed significantly high benefits
(HR 0.55; 95\% CI 0.36-0.84), compared to RFA and SR (HR 0.53; 95\% CI 0.44-0.66) in the non-RCTs subgroup (Additional file 7: Fig. S7). In addition, MIS (HR 0.60; 95\% CI 0.37-0.96) exhibited significantly more benefits with regards to OS outcomes, compared to WMA, SR (HR 0.75 ; 95\% CI 0.43-0.78). SR and MIS exhibited the highest cumulative probabilities of being ranked first and second, respectively. Overall ranking of most treatments based on efficacy was comparable to ranking results of all subgroups. The main difference was that SBRT had the highest cumulative probabilities of being ranked the worst intervention in achieving maximum OS outcome benefits in the $\leq 3 \mathrm{~cm}$ subgroup, whereas SBRT was ranked third in the other subgroups. 


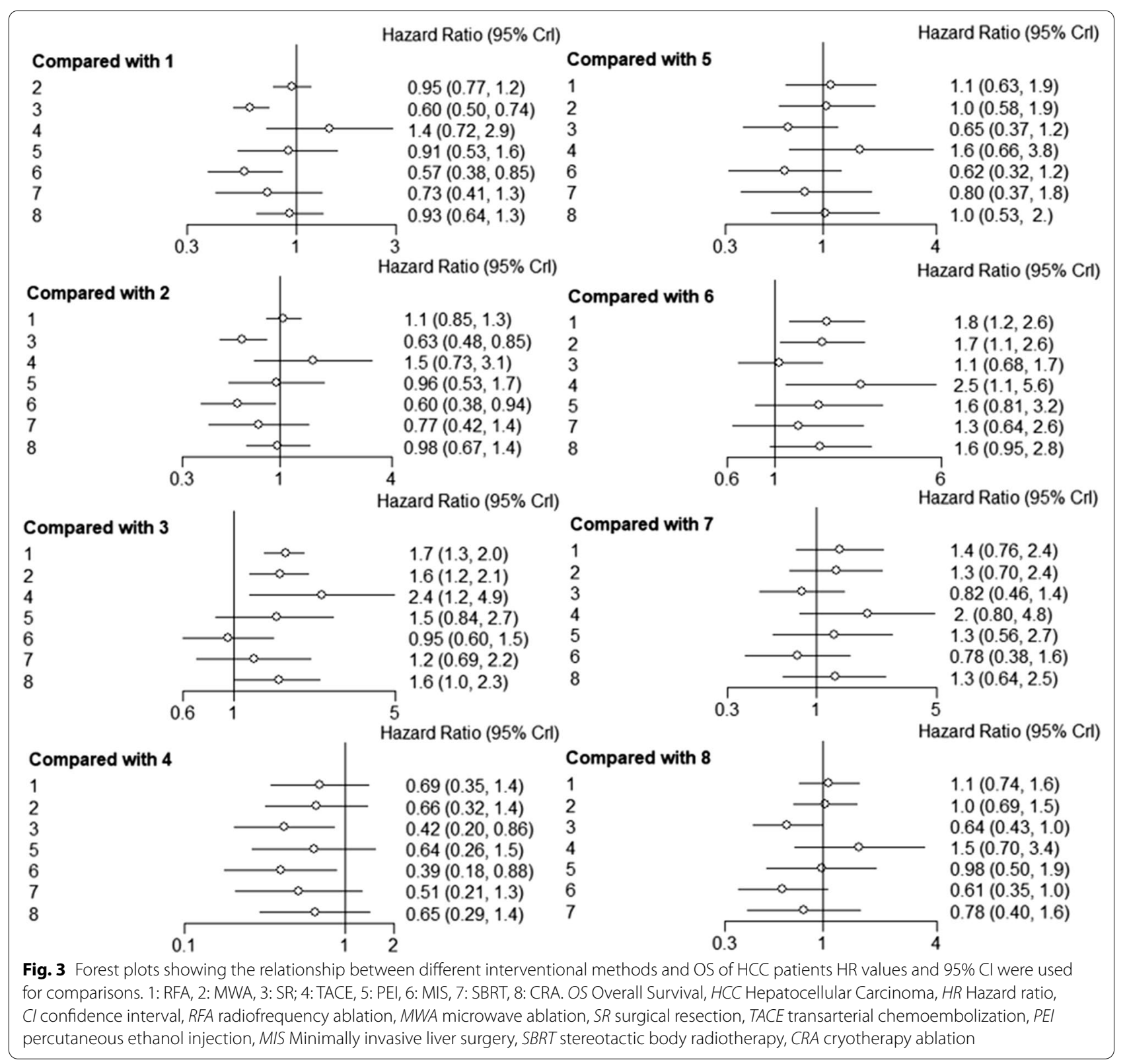

Subgroup analyses for studies that included RFS as an endpoint showed that MIS and SR was associated with significantly better RFS in RFS and DFS subgroups, compared to RFA. Pooled data based on DFS associated with the five treatments showed that RFA and MWA were associated with lower DFS, compared to SR (HR 0.70, 95\% CI 0.53-0.95; HR 0.65, 95\% CI 0.42-0.99, respectively) and MIS (HR 0.43, 95\% CI 0.22-0.85; HR 0.40, 95\% CI 0.19-0.83, respectively) (Additional file 8: Fig. S8). Seventeen studies comprising 7 treatments other than PEI reported on RFS outcomes (Additional file 9: Fig. S9). Network meta-analysis showed that both
SR and MIS were associated with significantly better RFS, compared to RFS outcomes associated with RFA (HR 0.55, 95\% CI 0.50-0.63; HR 0.49, 95\% CI 0.37-0.65, respectively), MWA (HR 0.58, 95\% CI 0.46-0.74; HR 0.52, 95\% CI 0.36-0.73, respectively), and CRA (HR 0.62, 95\% CI 0.45-0.88; HR 0.55, 95\% CI 0.35-0.94, respectively) treatments. In addition, SBRT was associated with better RFS outcomes, compared to RFA (HR 0.55, 95\% CI 0.350.86 ) and WMA (HR $0.5895 \%$ CI $0.35-0.94$ ). A total 8 studies evaluated 4 treatments, excluding TACE, PEI, MIS, and SBRT in RCTs subgroup (Additional file 10: Fig. S10). There were no significant differences in RFS* 


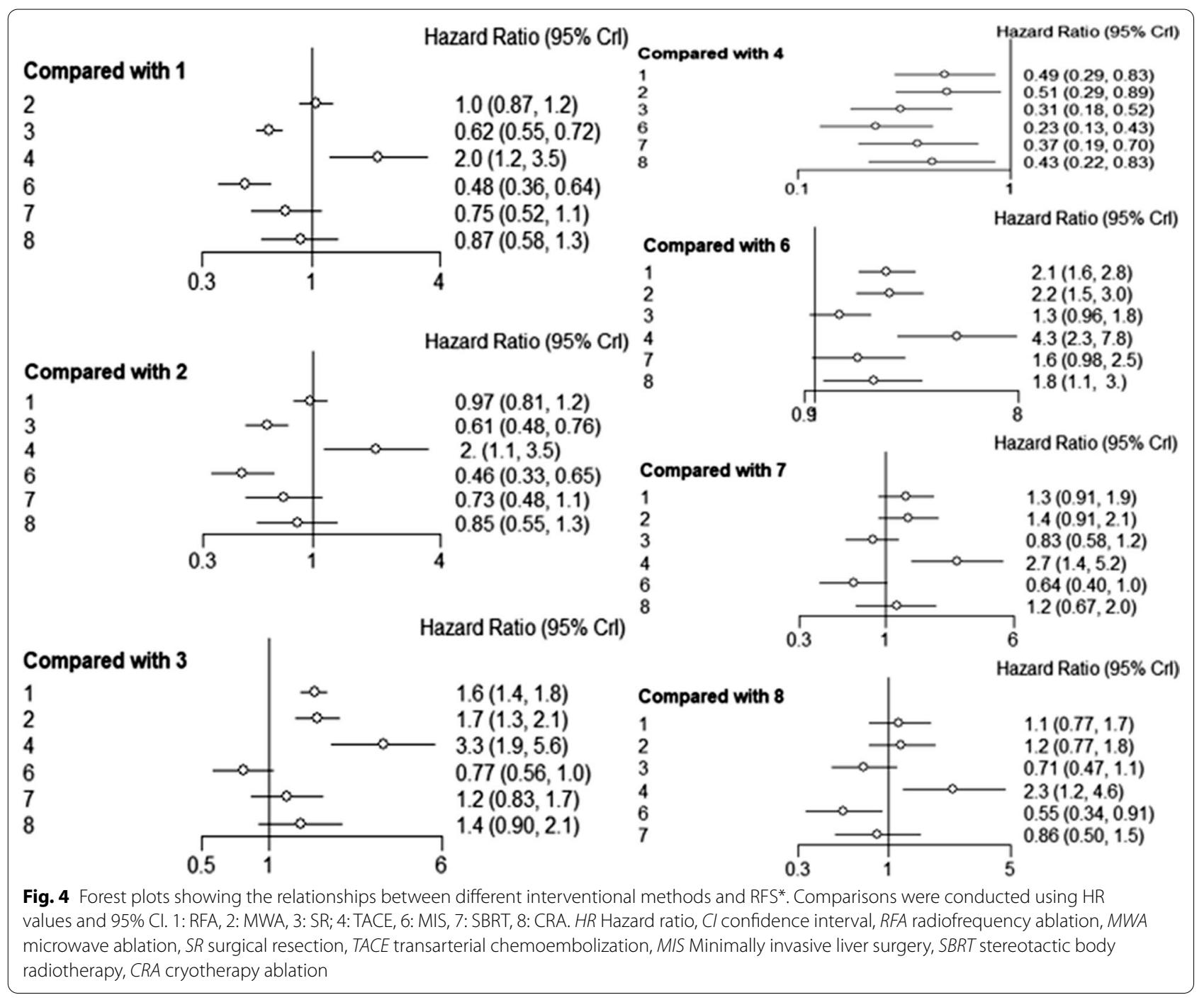

rate among the treatments. A total of 24 studies in the non-RCTs subgroup investigated 7 treatments, with the exception of PEI (Additional file 11: Fig. S11). Pooled data showed that SR (HR 0.58, 95\% CI 0.51-0.67; HR 0.55, 95\% CI 0.43-0.68, respectively) and MIS (HR 0.48, 95\% CI $0.36-0.63$; HR 0.44 , 95\% CI 0.31-0.62, respectively) were associated with higher RFS outcomes, compared to RFA and WMA interventions. A total of 17 studies in the $\mathrm{HCC} \leq 5 \mathrm{~cm}$ subgroup included 6 treatments and did not report TACE and PEI (Additional file 12: Fig. S12). Network meta-analysis showed that SR and MIS were associated with significantly high RFS, compared to RFA (HR 0.59, 95\% CI 0.50-0.72; HR 0.41, 95\% CI 0.25-0.70, respectively) and MWA (HR 0.59, 95\% CI 0.46-0.75; HR $0.41,95 \%$ CI $0.24-0.71$, respectively) interventions. The $\mathrm{HCC} \leq 3 \mathrm{~cm}$ subgroup (Additional file 13: Fig. S13) comprised 6 studies that reported findings on 4 treatments. Network meta-analysis showed that SR (HR 0.34, 95\% CI
0.12-0.96) and MIS (HR 0.22, 95\% CI 0.057-0.79) were associated with significantly higher RFS, compared to TACE intervention. Overall ranking of most treatments based on efficacy was similar to the ranking of all subgroups. The main difference was that MWA exhibited the highest cumulative probabilities of being ranked last in achieving maximum RFS benefits for the RCTs subgroup, whereas in most other subgroups MWA showed higher benefits, compared to some other treatments. Moreover, RFA was ranked above WMA in the RFS* group, whereas, WMA was ranked above RFA in other groups.

In addition, subgroup analyses were performed according to tumor sizes and study designs for severe complication rates. Analysis of studies in the RCT subgroup (Additional file 14: Fig. S14) involving 5 treatments (RFA, MWA, SR, PEI and CRA), showed that SR (RR 2.7, 95\% CI 1.1-8.0) was the only intervention that was associated with significantly poor outcomes in terms of reducing 


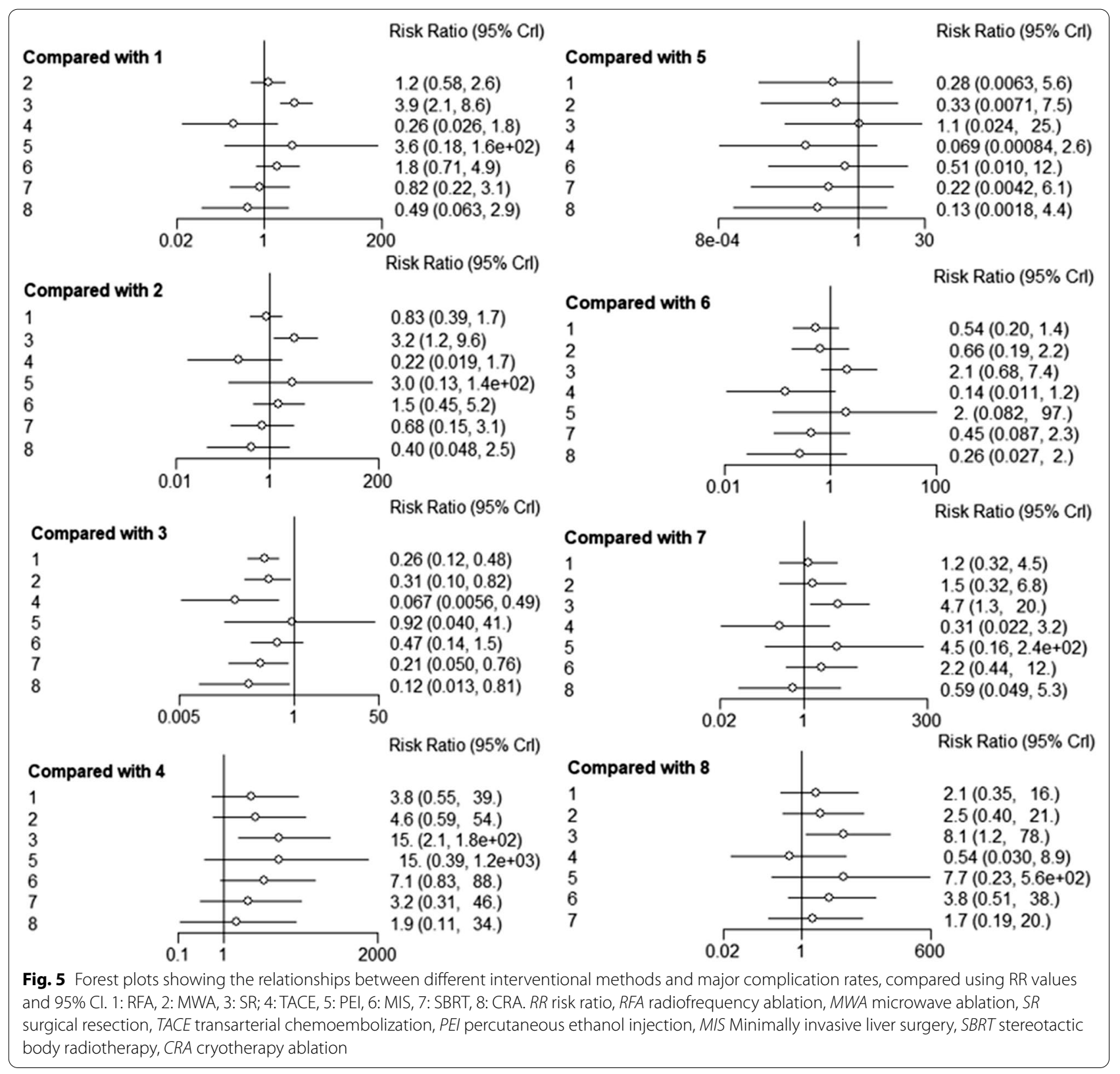

tumor sizes, compared to RFA. MWA exhibited the highest cumulative probabilities of being ranked first in reducing tumor sizes, whereas SR was ranked last. Pooled data for the non-RCT subgroup (Additional file 15: Fig. S15) comprising studies reporting 7 treatments with the exception of PEI showed less severe complications for RFA, MWA, TACE and SBRT compared to SR (RR 0.23, 95\% CI 0.085-0.51; RR 0.27, 95\% CI 0.067-0.88; RR 0.062, 95\% CI 0.0048-0.46; RR 0.21, 95\% CI 0.05-0.71, respectively). CRA exhibited the highest cumulative probabilities of being ranked first in alleviation of complications, whereas SR was ranked last.

\section{Discussion}

In this network meta-analysis, eight primary treatments for SHCC were compared through direct and indirect evidence reported in 45 studies involving 11,364 patients. Patients had tumor stages corresponding to BCLC 0 and BCLC A of the Barcelona Clinical Liver cancer (BCLC) staging system. Bayesian network meta-analysis showed that MIS and SR exhibited better OS and RFS outcomes, relative to the other non-surgical treatment methods. In addition, MIS was associated with better outcomes, compared to SR while SBRT was more effective at increasing RFS outcomes, relative to the other non-surgical 


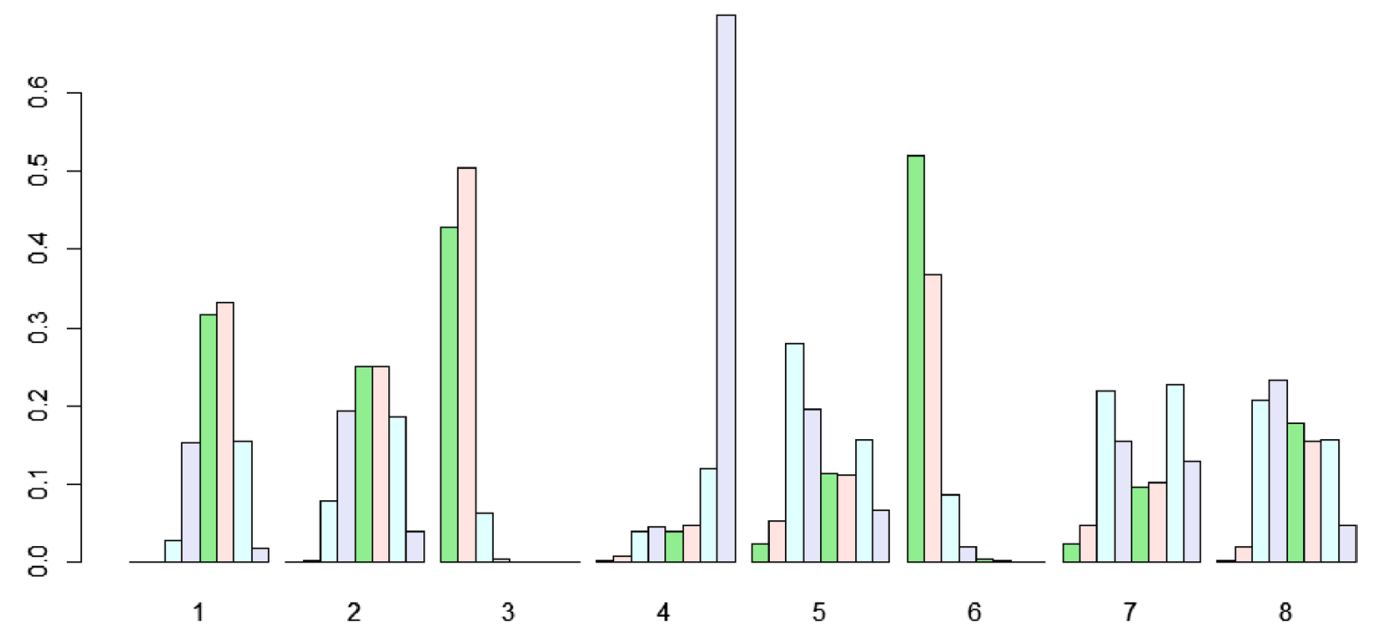

Fig. 6 Efficacy levels of different treatment approaches based on OS. 1: RFA, 2: MWA, 3: SR, 4: TACE, 5: PEI, 6: MIS, 7: SBRT, 8: CRA. OS Overall Survival, RFA radiofrequency ablation, MWA microwave ablation, SR surgical resection, TACE transarterial chemoembolization, $P E /$ percutaneous ethanol injection, MIS Minimally invasive liver surgery, SBRT stereotactic body radiotherapy, CRA cryotherapy ablation

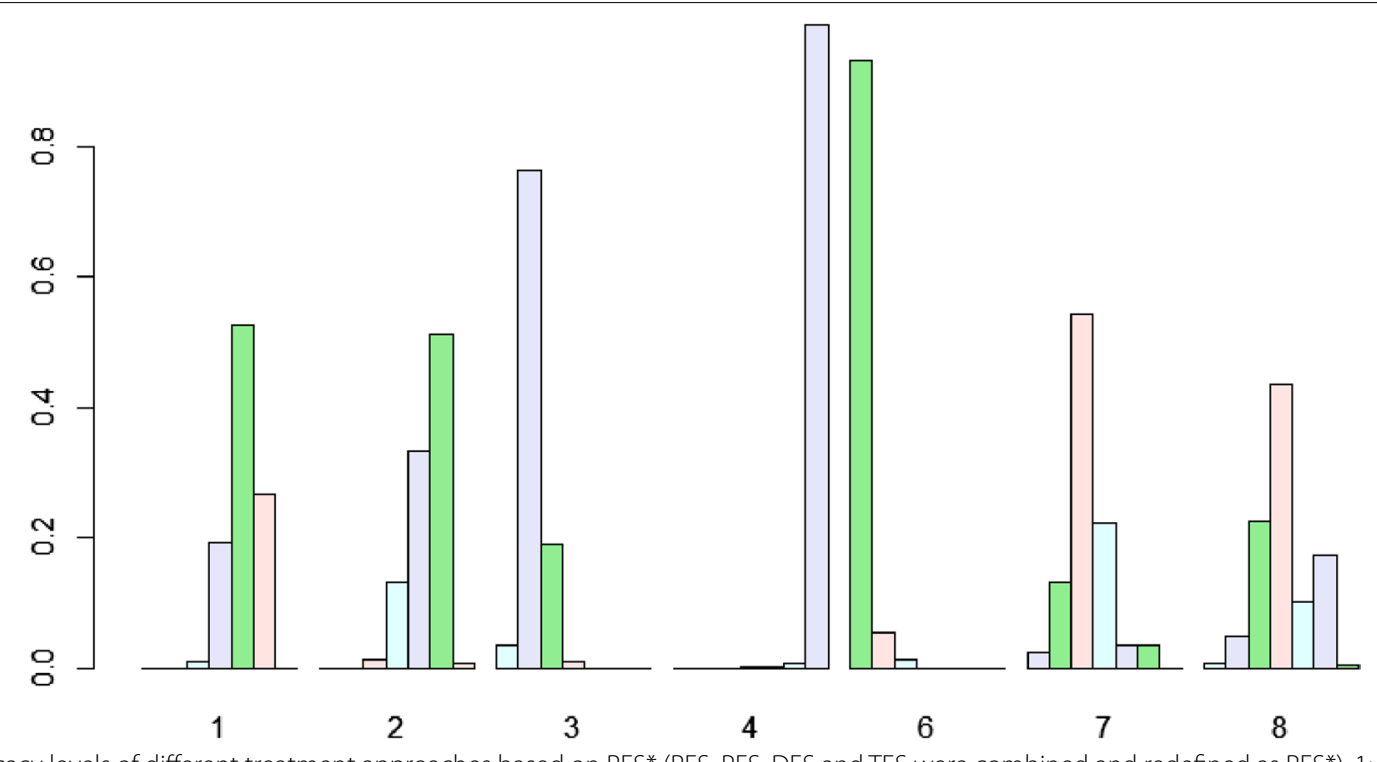

Fig. 7 Efficacy levels of different treatment approaches based on RFS* (RFS, PFS, DFS and TFS were combined and redefined as RFS*). 1: RFA, 2: MWA, 3: SR, 4: TACE, 6: MIS, 7: SBRT, 8: CRA. RFS recurrence-free survival, PFS progression-free survival, DFS disease free survival, TFS tumor-free survival, RFA radiofrequency ablation, MWA microwave ablation, SR surgical resection, TACE transarterial chemoembolization, MIS Minimally invasive liver surgery, SBRT stereotactic body radiotherapy, CRA cryotherapy ablation

treatment approaches, whereas TACE was associated with significantly poor RFS* outcomes, compared to the other six treatment methods. Subgroup analysis revealed that RFA was more effective in patients with small nodules ( $<2 \mathrm{~cm}$ or $3 \mathrm{~cm}$ in diameter). Notably, tumor nodule sizes were the main causes of heterogeneity. Borderline observations were made between MIS and CRA for OS
(HR 0.60, 95\% CI 0.36-1.00), and between MIS and SR for RFS* (HR 0.77, 95\% CI 0.56-1.00). Studies with larger sample sizes should be conducted to verify these findings. Findings from RCT and non-RCT subgroups were consistent with these findings. Subgroup analyses based on liver status (Child-Pugh score) [87], AFP, vascular invasion (the most important predictors of prognosis [88]), 


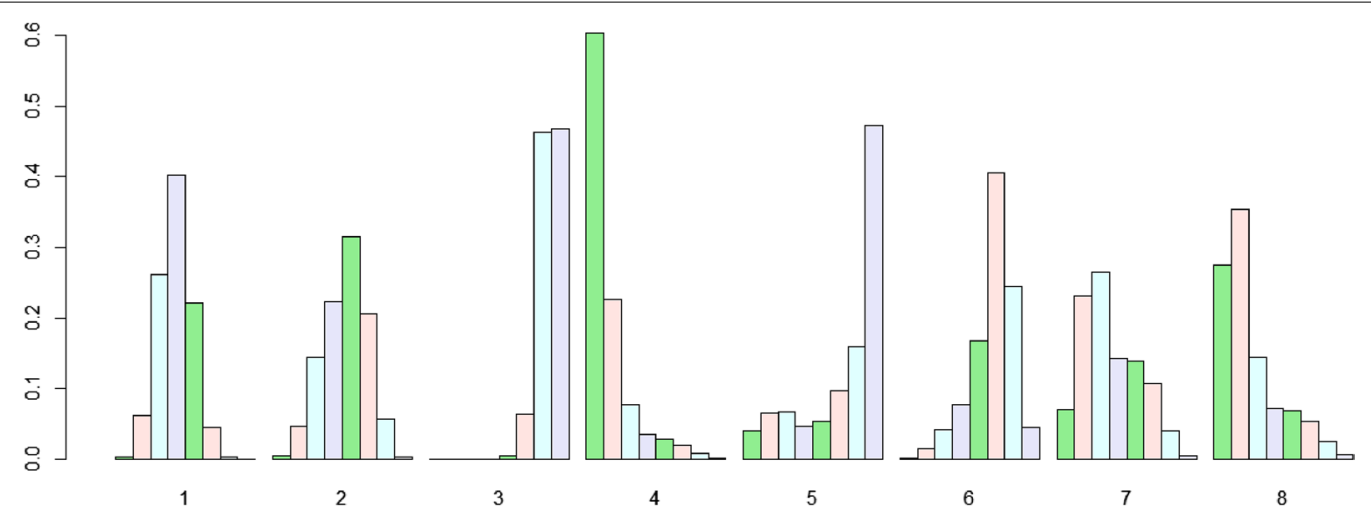

Fig. 8 Efficacy levels of different treatment approaches based on major complication rates. 1: RFA, 2: MWA, 3: SR, 4:TACE, 5: PEI, 6: MIS, 7: SBRT, 8: CRA. RFA radiofrequency ablation, MWA microwave ablation, SR surgical resection, TACE transarterial chemoembolization, PEl percutaneous ethanol injection, MIS Minimally invasive liver surgery, SBRT stereotactic body radiotherapy, CRA cryotherapy ablation

medical comorbidities and tumors sizes at 2 to $3 \mathrm{~cm}$ or 3 to $5 \mathrm{~cm}$ were not performed due to a lack of sufficient data. Well-designed, large-scale randomized controlled trials, including more subgroup analyses should be conducted. Ranking of the relative efficacy and safety for different treatment approaches provides a basis for making future clinical decisions for the most effective interventions for treatment of SHCC patients.

EORTC developed clinical practice guidelines that recommend SR and MIS as first line treatment options for SHCC [89, 90]. Surgical interventions involving the removal of the entire Couinaud segment containing tumors effectively eliminate the primary tumors. Therefore, cancer embolus and microscopic lesions are completely eliminated in patients who undergo surgery [91]. This may explain the relatively higher OS and RFS observed in SHCC patients treated by surgical interventions. However, the rates of complications such as bleeding, infection, and liver failure in patients subjected to surgical therapy are high. This finding is consistent with results from previous meta-analyses [92-94]. SR was associated with low recurrence rates and high survival rates, compared to RFA. However, SR was associated with a higher predisposition to severe complications, relative to RFA, although differences were not significant. Currently, there is no unified definition of surgical indications. Previous meta-analyses published in 2010 reported different results $[95,96]$. The differences can be attributed to the overall low level of clinical evidence, as most of the studies included in the current study were completed before 2010. Due to advances in interventional radiology in the last decade, loco-regional treatment has become an important alternative therapy for early HCC [17]. The European Association for the Study of the Liver (EASL) recommends RFA and MWA as standard treatment approaches for patients who are not eligible for surgery [6]. MWA uses electromagnetic waves from electrodes, whereas the effects of RFA are achieved by targeting current to the tumor. MWA and RFA are associated with several advantages, such as high tolerance, good repeatability, low complication rates and low initial costs [97-99]. Radiofrequency ablation is associated with some limitations in treatment of SHCC, including the diffusion-thermo effect. Diffusion-thermo effect is attributed to minimum blood vessel flow of $1 \mathrm{ml} / \mathrm{min}$ [100], and can lead to incomplete ablation [101]. It has been reported that MWA can alternate conventional radiofrequency ablation, and is highly effective in tumor treatment. A previous meta-analysis indicated that MWA has a lower LTP in larger nodules, compared to RFA [102]. In addition, studies explored complete ablation (CA), local recurrence (LR), PFS, and OS and reported that the efficacies of percutaneous RFA are comparable to those of percutaneous MWA [103]. This study included a high number of samples, performed direct and indirect comparisons, and showed similar outcomes with previous findings [103]. This implies that findings from this study are credible and accurate. In addition, we found that the efficacy and safety of MWA and RFA were comparable, even in $<2 \mathrm{~cm}$ or $<3 \mathrm{~cm}$ tumor subgroups. It has been documented that CRA has several advantages, including pain relief, immune effects enhancement, and good visualization of ablation areas. Moreover, a larger ablation area can be obtained by simultaneously placing multiple probes. However, due to various safety concerns, this method is not widely used [104]. Due to advances in ablation techniques, the applications of MWA and CRA for SHCC treatment are increasing. Our findings show that CRA exerted comparable efficacies and safety to those of MWA and RFA. Therefore, improvement of 
the techniques and understanding of their mechanisms can improve the therapeutic effects of existing treatment methods. Notably, the efficacies of PEI and RFA were not significantly different. However, previous studies reported that RFA has a higher effect, compared to PEI [92]. These differences in outcomes could be attributed to a lack of sufficient sample sizes, because only studies published in the past 10 years were included in this metaanalysis. As a result, this meta-analysis only included one study that reported PEI, resulting in a high risk of bias.

A network meta-analysis by Lin et al. [105] analyzed data in 5 RCTs and compared the efficacies of different interventional techniques for treatment of early stage hepatocellular carcinoma, including SR, RFA, MWA, PEI, CRA, laser ablation and external beam radiotherapy. However, in this previous meta-analysis, only RCTs were included, with some high-quality cohort studies being excluded. Furthermore, the study focused on comparing the efficacy of ablation and the studies included in the meta-analysis were published over a large period of time, therefore, technological developments may have resulted in heterogeneity. In addition, the risk ratio (RR) was used as the effect indicator, which may have resulted in errors during survival analysis. A previous NMA compared the efficacies of therapies for SHCC, however, MWA and CRA were not included in the analysis [106]. Moreover, studies published before February 2015 were included in the analysis, with recent studies being excluded. Previous studies recommend the use of SBRT for treatment of HCC that is characterized by relatively large tumors $(>2-3 \mathrm{~cm}$ in diameter) as well as for tumors near major vessels or the diaphragm, which is a contraindication for RFA [107-109]. We found that there were no significant differences in efficacies between SBRT and RFA, implying that the effects of confounding factors cannot be completely eliminated. In addition, SBRT is mainly applicable for patients who are not clinically eligible for RFA [109]. These results provide a reference for future research and clinical decision making. However, due to the effects of several confounding factors (such as race, age, facility location, and time of diagnosis), the findings should be treated with caution.

This study has several strengths and a few limitations. $i$. The strength of this study is that cumulative OS and RFS were compared by calculating HRs (hazard rates), which are the most appropriate parameters for determining time-dependent outcomes $[110,111]$. However, HRs were extracted from survival curves, which provided survival information, leading to potential errors. ii. The main limitation for this study is that the included RCTs were few, while most included studies were nonRCTs, resulting in potential unpredictable confounding factors. Notably, the best evidence in oncology is not always based on randomized trials, and reliable data are reported in retrospective studies. In addition, a previous meta-analysis [112] and findings from the study indicated that observational studies mainly produce estimates of effects that are not significantly different from RCTs. Moreover, an important strength of this study is in the overall high methodological quality of the included trials. iii. The current study comprised a large total sample size, however, sample sizes for some treatments were small, implying that some of the findings may not be representative of other populations. Therefore, they should be interpreted with caution. Furthermore, absolute differences among different treatments may be trivial, whereas one treatment may be rated as the best. iv. Further, the study included eight major treatments for SHCC in the analysis. Notably, comparisons of various interventions in SHCC patients may not indicate the benefits of patients from multiple interventions, including combinations of surgical approaches and systemic treatment methods. v. Advances in technology will lead to improved therapeutic effects. Notably, a technology that has been used for a short time may have a disadvantage over a fully developed technology. The current study excluded articles published before 2010, which reduces publication bias to some extent. vi. Data estimated by propensity score matching, and adjusting for potential differences in baseline characteristics of patients was performed to create a highly comparable control group in the meta-analysis. However, most factors were not related to tumor control. Management decisions for SHCC mainly rely on informed preferences of patients and levels of expertise of different medical facilities. vii. Furthermore, we conducted subgroup analysis based on study types, tumor sizes and outcomes. However, due to insufficient data, subgroup analyses or regression analyses were not conducted on some of the factors that may have affected patient outcomes.

\section{Conclusions}

The findings of this network meta-analysis indicated that MIS and SR exhibit high clinical efficacies, however, these two approaches are correlated with a high number of complications. Ablation is highly effective for small tumors, whereas SBRT is more effective when compared to other ablation treatments in some cases. This indicates that SBRT is a relatively promising treatment for HCC. Subgroup analysis indicated that further studies should explore indications for different treatments. Moreover, well-designed, large-scale randomized controlled trials should be conducted to validate the findings of this study. 


\section{Supplementary Information}

The online version contains supplementary material available at https://doi. org/10.1186/s12935-021-02365-1.

Additional file 1: Figure S1: Quality assessment of included RCTs using Cochrane risk of bias assessment tool. RCTs: randomized controlled trials.

Additional file 2: Figure S2. Funnel plot showing standard error by RR for major complication rates. RR: risk ratio.

Additional file 3: Figure S3. Results on convergence of Gelman Rubin diagnostics. A: Results on OS; B: Results on RFS* (RFS, PFS, DFS and TFS were combined and redefined as RFS*); $\mathrm{C}$ : Results on major complications rate. 1: RFA, 2: MWA, 3: SR, 4: TACE, 5: PEI, 6: MIS, 7: SBRT, 8: CRA. The level of adequacy of convergence of Gelman Rubin diagnostics approached 1 for all the three outcome parameters, indicating good convergence. OS: Overall Survival, RFS: recurrence-free survival, PFS: progression-free survival, DFS: disease free survival, TFS, tumor-free survival, RFA: radiofrequency ablation, MWA: microwave ablation, SR: surgical resection, TACE: transarterial chemoembolization, PEl: percutaneous ethanol injection, MIS: Minimally invasive liver surgery, SBRT: stereotactic body radiotherapy, CRA: cryotherapy ablation.

Additional file 4: Figure S4. Forest plots showing relationships between different interventional methods and OS for subgroup analyses (HCCS tumor size $\leq 5 \mathrm{~cm}$ ), compared to RFA and MWA. HR values and $95 \%$ CI were used. 1: RFA, 2: MWA, 3: SR, 6: MIS, 7: SBRT, 8: CRA. OS: Overall Survival, HCC: Hepatocellular Carcinoma, RFA: radiofrequency ablation, MWA: microwave ablation, HR: Hazard ratio, SR: surgical resection, MIS: Minimally invasive liver surgery, SBRT: stereotactic body radiotherapy, CRA: cryotherapy ablation.

Additional file 5: Figure S5. Forest plots showing the relationship between different interventional methods and OS for subgroup analyses (HCCs tumor size $\leq 3 \mathrm{~cm}$ ) compared to RFA. HR values and $95 \% \mathrm{Cl}$ were used for comparisons. 1: RFA, 3: SR, 4: TACE, 5: PEI, 6: MIS, 7: SBRT. OS: Overall Survival, HCC: Hepatocellular carcinoma, RFA: radiofrequency ablation, HR: Hazard ratio, SR: surgical resection, TACE: transarterial chemoembolization, PEl: percutaneous ethanol injection, MIS: Minimally invasive liver surgery, SBRT: stereotactic body radiotherapy.

Additional file 6: Figure S6. Forest plots showing the relationship between different interventional methods and OS for subgroup analyses (RCTs) compared to RFA. HR values and $95 \% \mathrm{Cl}$ were used for comparisons. 1: RFA, 2: MWA, 3: SR, 5: PEI, 8: CRA. OS: Overall Survival, RCTs: randomized controlled trials, RFA: radiofrequency ablation, HR: Hazard ratio, MWA microwave ablation, SR: surgical resection, PEl: percutaneous ethanol injection, CRA: cryotherapy ablation.

Additional file 7: Figure S7. Forest plots showing the relationship between different interventional approaches and OS for subgroup analyses (non-RCTs), compared to RFA and MWA. HR values and 95\% Cl were used for comparisons. 1: RFA, 2: MWA, 3: SR, 4:TACE, 6: MIS, 7: SBRT, 8: CRA. OS: Overall Survival, non-RCTs: non-randomized controlled trials, RFA: radiofrequency ablation, MWA: microwave ablation, HR: Hazard ratio, SR: surgical resection, TACE: transarterial chemoembolization, MIS: Minimally invasive liver surgery, SBRT: stereotactic body radiotherapy, CRA: cryotherapy ablation.

Additional file 8: Figure S8. Forest plots showing the relationship between different interventional methods and DFS, compared to RFA and MWA. HR values and 95\% Cl were used for comparisons. 1: RFA, 2: MWA, 3: SR, 6: MIS, 7: SBRT. DFS: disease free survival, RFA: radiofrequency ablation, MWA: microwave ablation, HR: Hazard ratio, Cl: confidence interval, SR: surgical resection, MIS: Minimally invasive liver surgery, SBRT: stereotactic body radiotherapy.

Additional file 9: Figure S9. Forest plots showing the relationship between different interventional methods and RFS, compared to RFA, MWA and CRA. HR values and $95 \% \mathrm{Cl}$ were used for comparisons. 1: RFA, 2: MWA, 3: SR, 4: TACE, 6: MIS, 7: SBRT, 8: CRA. RFS: recurrence-free survival, RFA: radiofrequency ablation, MWA: microwave ablation, HR: Hazard ratio, Cl: confidence interval, SR: surgical resection, TACE: transarterial chemoembolization, MIS: Minimally invasive liver surgery, SBRT: stereotactic body radiotherapy.

Additional file 10: Figure S10. Forest plots showing the association between different interventional methods and RFS* (RFS, PFS, DFS and TFS were combined and redefined as RFS*) for subgroup analyses (RCTs), compared to RFA. HR values and $95 \% \mathrm{Cl}$ were used for comparisons. 1 : RFA, 2: MWA, 3: SR, 8: CRA. RFS: recurrence-free survival, PFS: progressionfree survival, DFS: disease free survival, TFS, tumor-free survival, RCTs: randomized controlled trials, RFA: radiofrequency ablation, HR: Hazard ratio, Cl: confidence interval, MWA: microwave ablation, SR: surgical resection, CRA: cryotherapy ablation.

Additional file 11: Figure S11. Forest plots showing the association between different interventional methods and RFS* (RFS, PFS, DFS and TFS were combined and redefined as RFS*) for subgroup analyses (nonRCTs), compared to RFA and MWA. HR values and $95 \% \mathrm{Cl}$ were used for comparisons. 1: RFA, 2: MWA, 3: SR, 4: TACE, 6: MIS, 7: SBRT, 8: CRA. RFS: recurrence-free survival, PFS: progression-free survival, DFS: disease free survival, TFS, tumor-free survival, non-RCTs: non-randomized controlled trials, RFA: radiofrequency ablation, MWA: microwave ablation, HR: Hazard ratio, Cl: confidence interval, SR: surgical resection, TACE: transarterial chemoembolization, MIS: Minimally invasive liver surgery, SBRT: stereotactic body radiotherapy, CRA: cryotherapy ablation.

Additional file 12: Figure S12. Forest plots showing the association between different interventional arms and RFS* (RFS, PFS, DFS and TFS were combined and redefined as RFS*) for subgroup analyses (HCCS tumor size $\leq 5 \mathrm{~cm}$ ), compared to RFA and MWA. HR values and 95\% CI were used for comparisons. 1: RFA, 2: MWA, 3: SR, 6: MIS, 7: SBRT, 8: CRA. RFS: recurrence-free survival, PFS: progression-free survival, DFS: disease free survival, TFS, tumor-free survival, HCC: Hepatocellular Carcinoma, RFA: radiofrequency ablation, MWA: microwave ablation, HR: Hazard ratio, Cl: confidence interval, SR: surgical resection, MIS: Minimally invasive liver surgery, SBRT: stereotactic body radiotherapy, CRA: cryotherapy ablation.

Additional file 13: Figure S13. Forest plots showing the association between different interventional approaches and RFS* (RFS, PFS, DFS and TFS were combined and redefined as RFS*) for subgroup analyses (HCCS tumor size $\leq 3 \mathrm{~cm}$ ), compared to TACE. HR values and $95 \% \mathrm{Cl}$ were used for comparisons. 1: RFA, 3: SR, 4: TACE, 6: MIS. RFS: recurrence-free survival, PFS: progression-free survival, DFS: disease free survival, TFS, tumor-free survival, HCC: Hepatocellular Carcinoma, TACE: transarterial chemoembolization, HR: Hazard ratio, Cl: confidence interval, RFA: radiofrequency ablation, SR: surgical resection, MIS: Minimally invasive liver surgery.

Additional file 14: Figure S14. Forest plots showing the association between different interventional methods and major complication rates in subgroup analyses (RCTs), compared to RFA. RR values and 95\% CI were used for comparisons. 1: RFA, 2: MWA, 3: SR, 5: PEl, 8: CRA. RCTs: randomized controlled trials, RFA: radiofrequency ablation, RR: risk ratio, MWA: microwave ablation, SR: surgical resection, PEl: percutaneous ethanol injection, CRA: cryotherapy ablation.

Additional file 15: Figure S15. Forest plots showing the association between different interventional approaches and major complications rate for subgroup analyses (non-RCTs), compared to RFA. RR values and 95\% Cl were used for comparisons. 1: RFA, 2: MWA, 3: SR, 4: TACE, 6: MIS, 7: SBRT, 8: CRA. non-RCTs: non-randomized controlled trials, RFA: radiofrequency ablation, RR: risk ratio, MWA: microwave ablation, SR: surgical resection, TACE: transarterial chemoembolization, MIS: Minimally invasive liver surgery, SBRT: stereotactic body radiotherapy, CRA: cryotherapy ablation.

Additional file 15: Table S1. The inconsistent loops P-value for different comparisons.

\section{Acknowledgements}

We thank all of the patients and authors involved in the included study. 


\section{Authors' contributions}

SY designed the manuscript, analyzed the data, and wrote the paper. HL performed the statistical measurements. JS designed and evaluated the manuscript.

\section{Funding}

No funding was provided.

\section{Availability of data and materials \\ Not applicable.}

\section{Declarations}

\section{Ethics approval and consent to participate:}

Not applicable.

\section{Consent for publication}

Not applicable.

\section{Competing interests}

The authors declare that they have no competing interests.

\begin{abstract}
Author details
'Department of Surgery, Children's Hospital of Chongqing Medical University, Chongqing, People's Republic of China. ${ }^{2}$ Department of Intensive Care Unit, Affiliated Hangzhou First People's Hospital, Zhejiang University School of Medicine, Hangzhou, China. ${ }^{3}$ Department of General Surgery, Guiqian International General Hospital, 1 Dongfeng Dadao, Wudang District, Guiyang, Guizhou 550018, People's Republic of China. ${ }^{4}$ Ministry of Education Key Laboratory of Child Development and Disorders, Chongqing, People's Republic of China. ${ }^{5}$ National Clinical Research Center for Child Health and Disorders, Chongqing, People's Republic of China. ${ }^{6}$ China International Science and Technology Cooperation Base of Child Development and Critical Disorders, Chongqing, People's Republic of China. ${ }^{7}$ Chongqing Key Laboratory of Pediatrics, Chongqing, People's Republic of China. ${ }^{8}$ Chongqing Engineering Research Center of Stem Cell Therapy, Chongqing, People's Republic of China. ${ }^{9}$ Children S Hospital of Chongqing Medical University, Chongqing, People's Republic of China.
\end{abstract}

Received: 17 Auqust 2021 Accepted: 25 November 2021 Published online: 19 December 2021

\section{References}

1. International Agency for Research on Cancer, World Health Organization. Cancer today. https://gco.iarc.fr/today/home.

2. World Health Organization. Projections of mortality and causes of death, 2016 to 2060. http://www.who.int/healthinfo/global_burden_ disease/projections/en/.

3. Centers for Disease Control and Prevention, National Center for Health Statistics. Trends in liver cancer mortality among adults aged 25 and over in the United States, 2000 2016. July 2018. https://www.cdc.gov/ nchs/products/databriefs/db314.htm.

4. Mehta N, Guy J, Frenette CT, Dodge JL, Osorio RW, Minteer WB, Roberts JP, Yao FY. Excellent outcomes of liver transplantation following downstaging of hepatocellular carcinoma to within Milan criteria: a multicenter study. Clin Gastroenterol Hepatol. 2018;16(6):955-64. https://doi. org/10.1016/j.cgh.2017.11.037 (Epub 2017 Nov 23).

5. Organ Procurement and Transplantation Network. Policies. 2020. https://optn.transplant.hrsa.gov/media/1200/optn_policies.pdf.

6. European Association for the Study of the Liver. Electronic address: easloffice@easloffice.eu; European Association for the Study of the Liver. EASL Clinical Practice Guidelines: Management of hepatocellular carcinoma. J Hepatol. 2018 Jul;69(1):182-236. doi: https://doi.org/10. 1016/j.jhep.2018.03.019. Epub 2018 Apr 5. Erratum in: J Hepatol. 2019 Apr;70(4):817

7. Marrero JA, Kulik LM, Sirlin CB, Zhu AX, Finn RS, Abecassis MM, Roberts LR, Heimbach JK. Diagnosis, staging, and management of hepatocellular carcinoma: 2018 practice guidance by the American Association for the Study of Liver Diseases. Hepatology. 2018;68(2):72350. https://doi.org/10.1002/hep.29913.

8. DelPiccolo N, Onkendi E, Nguyen J, Patel S, Asbun HJ, Burns J, Croome K, Obi JR, Stauffer JA. Outcomes of minimally invasive versus open major hepatic resection. J Laparoendosc Adv Surg Tech A. 2020;30(7):790-6. https://doi.org/10.1089/lap.2019.0615 (Epub 2020 Apr 23).

9. Bauschke A, Kissler H, Settmacher U. Minimal-invasive Leberchirurgie [Minimally invasive liver surgery]. Chirurg. 2021;92(9):853-60. https:// doi.org/10.1007/s00104-021-01380-2 (Epub 2021 Mar 30).

10. Deng ZC, Jiang WZ, Tang XD, Liu SH, Qin L, Qian HX. Laparoscopic hepatectomy versus open hepatectomy for hepatocellular carcinoma in 157 patients: a case controlled study with propensity score matching at two Chinese centres. Int J Surg. 2018;56:203-7. https://doi.org/10.1016/j.ijsu. 2018.06.026 (Epub 2018 Jun 20).

11. Tsai KY, Chen HA, Wang WY, Huang MT. Long-term and short-term surgical outcomes of laparoscopic versus open liver resection for hepatocellular carcinoma: might laparoscopic approach be better in early HCC? Surg Endosc. 2019;33(4):1131-9. https://doi.org/10.1007/ s00464-018-6372-0 (Epub 2018 Jul 24).

12. Brandi G, Rizzo A, Dall Olio FG, Felicani C, Ercolani G, Cescon M, Frega G, Tavolari S, Palloni A, De Lorenzo S, Abbati F, Mollica V, Ricci AD, Serra C. Percutaneous radiofrequency ablation in intrahepatic cholangiocarcinoma: a retrospective, single-center experience. Inter J Hyperthermia. 2020;37(1):479-85. https://doi.org/10.1080/02656736.2020.1763484.

13. Chang YJ, Chen LJ, Chang YJ, Chen PD. Population-based matching comparison between radiofrequency ablation and percutaneous ethanol or acetic acid injection for hepatocellular carcinoma. Eur J Surg Oncol. 2020;46(9):1703-10. https://doi.org/10.1016/j.ejso.2020.04.039 (Epub 2020 Apr 25).

14. Feng J, Qi X, Guo X, Qi X. Early-stage hepatocellular carcinoma: radiofrequency ablation or resection? Am J Gastroenterol. 2019;114(2):359. https://doi.org/10.14309/ajg.0000000000000131.

15. Mukund A, Vats P, Jindal A, Patidar Y, Sarin SK. Early hepatocellular carcinoma treated by radiofrequency ablation-mid- and long-term outcomes. J Clin Exp Hepatol. 2020;10(6):563-73. https://doi.org/10. 1016/j.jceh.2020.04.016 (Epub 2020 May 4).

16. Weinstein JL, Ahmed M. Percutaneous ablation for hepatocellular carcinoma. AJR Am J Roentgenol. 2018;210(6):1368-75. https://doi.org/ 10.2214/AJR.17.18695 (Epub 2018 Apr 27).

17. Inchingolo R, Posa A, Mariappan M, Spiliopoulos S. Locoregional treatments for hepatocellular carcinoma: current evidence and future directions. World J Gastroenterol. 2019;25(32):4614-28. https://doi.org/ 10.3748/wjg.v25.i32.4614.

18. Kalra N, Gupta P, Gorsi U, Bhujade H, Chaluvashetty SB, Duseja A, Singh V, Dhiman RK, Chawla YK, Khandelwal N. Irreversible electroporation for unresectable hepatocellular carcinoma: initial experience. Cardiovasc Intervent Radiol. 2019;42(4):584-90. https://doi.org/10.1007/s00270019-02164-2 (Epub 2019 Jan 29).

19. Shiina S, Sato K, Tateishi R, Shimizu M, Ohama H, Hatanaka T, Takawa M, Nagamatsu H, Imai Y. Percutaneous ablation for hepatocellular carcinoma: comparison of various ablation techniques and surgery. Can J Gastroenterol Hepatol. 2018;3(2018):4756147. https://doi.org/10.1155/ 2018/4756147.

20. Yu J, Yu XL, Han ZY, Cheng ZG, Liu FY, Zhai HY, Mu MJ, Liu YM, Liang P. Percutaneous cooled-probe microwave versus radiofrequency ablation in early-stage hepatocellular carcinoma: a phase III randomised controlled trial. Gut. 2017;66(6):1172-3. https://doi.org/10.1136/gutjnl2016-312629 (Epub 2016 Nov 24).

21. Liu W, Zheng Y, He W, Zou R, Qiu J, Shen J, Yang Z, Zhang Y, Wang C, Wang Y, Zuo D, Li B, Yuan Y. Microwave vs radiofrequency ablation for hepatocellular carcinoma within the Milan criteria: a propensity score analysis. Aliment Pharmacol Ther. 2018;48(6):671-81. https://doi.org/10. 1111/apt.14929 (Epub 2018 Jul 31).

22. Kang TW, Lim HK, Cha DI. Percutaneous ablation for perivascular hepatocellular carcinoma: refining the current status based on emerging evidence and future perspectives. World J Gastroenterol. 2018;24(47):5331-7. https://doi.org/10.3748/wjg.v24.i47.5331.

23. Kim R, Kang TW, Cha DI, et al. Percutaneous cryoablation for perivascular hepatocellular carcinoma: therapeutic efficacy and vascular 
complications. Eur Radiol. 2019;29:654-62. https://doi.org/10.1007/ s00330-018-5617-6.

24. Glazer DI, Tatli S, Shyn PB, Vangel MG, Tuncali K, Silverman SG. Percutaneous image-guided cryoablation of hepatic tumors: single-center experience with intermediate to long-term outcomes. AJR Am J Roentgenol. 2017;209(6):1381-9. https://doi.org/10.2214/AJR.16.17582 (Epub 2017 Sep 27)

25. Xu Y, Shen Q, Liu P, Xu Z, Wu P, Lu Z, Chen Y, Huang B, Qian G. Microwave ablation for the treatment of hepatocellular carcinoma that met up-to-seven criteria: feasibility, local efficacy and long-term outcomes. Eur Radiol. 2017;27(9):3877-87. https://doi.org/10.1007/s00330-0174740-0 (Epub 2017 Feb 10)

26. Yang JD, Hainaut P, Gores GJ, Amadou A, Plymoth A, Roberts LR. A global view of hepatocellular carcinoma: trends, risk, prevention and management. Nat Rev Gastroenterol Hepatol. 2019;16:589-604. https:// doi.org/10.1038/s41575-019-0186-y.

27. Lee J, Shin IS, Yoon WS, Koom WS, Rim CH. Comparisons between radiofrequency ablation and stereotactic body radiotherapy for liver malignancies: meta-analyses and a systematic review. Radiother Oncol. 2020;145:63-70. https://doi.org/10.1016/j.radonc.2019.12.004 (Epub 2020 Jan 7).

28. Rim CH, Kim HJ, Seong J. Clinical feasibility and efficacy of stereotactic body radiotherapy for hepatocellular carcinoma: a systematic review and meta-analysis of observational studies. Radiother Oncol. 2019;131:135-44. https://doi.org/10.1016/j.radonc.2018.12.005 (Epub 2018 Dec 31).

29. Ikeda M, Kudo M, Aikata H, Nagamatsu H, Ishii H, Yokosuka O, Torimura T, Morimoto M, Ikeda K, Kumada H, Sato T, Kawai I, Yamashita T, Horio H, Okusaka T, Miriplatin TACE Study Group. Transarterial chemoembolization with miriplatin vs. epirubicin for unresectable hepatocellular carcinoma: a phase III randomized trial. J Gastroenterol. 2018;53(2):281-90. https://doi.org/10.1007/s00535-017-1374-6 (Epub 2017 Aug 1).

30. Lencioni R, de Baere T, Soulen MC, Rilling WS, Geschwind JF. Lipiodol transarterial chemoembolization for hepatocellular carcinoma: a systematic review of efficacy and safety data. Hepatology. 2016;64(1):10616. https://doi.org/10.1002/hep.28453 (Epub 2016 Mar 7).

31. Llovet JM, Real MI, Montaña X, Planas R, Coll S, Aponte J, Ayuso C, Sala M, Muchart J, Solà R, Rodés J, Bruix J, Barcelona Liver Cancer Group. Arterial embolisation or chemoembolisation versus symptomatic treatment in patients with unresectable hepatocellular carcinoma: a randomised controlled trial. Lancet. 2002;359(9319):1734-9. https://doi. org/10.1016/S0140-6736(02)08649-X.

32. Heinecke A, Tallarita M, De lorio M. Bayesian splines versus fractional polynomials in network meta-analysis. BMC Med Res Methodol. 2020;20(1):261. https://doi.org/10.1186/s12874-020-01113-9.

33. Moher D, Shamseer L, Clarke M, Ghersi D, Liberati A, Petticrew M, Shekelle P, Stewart LA, PRISMA-P Group. Preferred reporting items for systematic review and meta-analysis protocols (PRISMA-P) 2015 statement. Syst Rev. 2015;4(1):1. https://doi.org/10.1186/2046-4053-4-1.

34. Hutton B, Salanti G, Caldwell DM, Chaimani A, Schmid CH, Cameron C, loannidis JP, Straus S, Thorlund K, Jansen JP, Mulrow C, Catalá-López F, Gøtzsche PC, Dickersin K, Boutron I, Altman DG, Moher D. The PRISMA extension statement for reporting of systematic reviews incorporating network meta-analyses of health care interventions: checklist and explanations. Ann Intern Med. 2015;162(11):777-84. https://doi.org/10. 7326/M14-2385

35. Wells GA, Shea B, O Connell D, Peterson J, Welch V, Losos M, et al. The Newcastle-Ottawa Scale (NOS) for assessing the quality of nonrandomized studies in meta- analyses. 2000. www.ohri.ca/programs/clini cal_epidemiology/nosgen.pdf. Accessed 27 Jul 2015.

36. Higgins JP, Altman DG, Gøtzsche PC, Jüni P, Moher D, Oxman AD, Savovic J, Schulz KF, Weeks L, Sterne JA, Cochrane Bias Methods Group; Cochrane Statistical Methods Group. The Cochrane Collaboration's tool for assessing risk of bias in randomised trials. BMJ. 2011;343:d5928. https://doi.org/10.1136/bmj.d5928.

37. Balieiro Anastacio da Costa AA, Baiocchi G, Guimarães APG. Progression-free survival in the ICON8 trial. Lancet. 2020;396(10253):756-7. https://doi.org/10.1016/S0140-6736(20)31176-4 (Erratum in: Lancet. 2020 Oct 3;396(10256):e56)

38. Shamsaeefar A, Nikeghbalian S, Kazemi K, Gholami S, Motazedian N, Motazedian N, Fallahzadeh ME, Moini M, Gramizadeh B, Malekhosseini
SA. Predictors of tumor-free survival after liver transplant in patient with hepatocellular carcinoma. Exp Clin Transplant. 2015;13(Suppl 1):139-44.

39. Cooper K, Tappenden P, Cantrell A, Ennis K. A systematic review of meta-analyses assessing the validity of tumour response endpoints as surrogates for progression-free or overall survival in cancer. $\mathrm{Br} J$ Cancer. 2020;123(11):1686-96. https://doi.org/10.1038/s41416-020-01050-w (Epub 2020 Sep 11).

40. Higgins JP, Jackson D, Barrett JK, Lu G, Ades AE, White IR. Consistency and inconsistency in network meta-analysis: concepts and models for multi-arm studies. Res Synth Methods. 2012;3(2):98-110. https://doi. org/10.1002/jrsm.1044.

41. Jansen JP, Crawford B, Bergman G, Stam W. Bayesian meta-analysis of multiple treatment comparisons: an introduction to mixed treatment comparisons. Value Health. 2008;11(5):956-64. https://doi.org/10.1111/j. 1524-4733.2008.00347.x (Epub 2008 May 16).

42. Dias S, Welton NJ, Caldwell DM, Ades AE. Checking consistency in mixed treatment comparison meta-analysis. Stat Med. 2010;29(78):932-44. https://doi.org/10.1002/sim.3767.

43. Vietti Violi N, Duran R, Guiu B, Cercueil JP, Aubé C, Digklia A, Pache I, Deltenre P, Knebel JF, Denys A. Efficacy of microwave ablation versus radiofrequency ablation for the treatment of hepatocellular carcinoma in patients with chronic liver disease: a randomised controlled phase 2 trial. Lancet Gastroenterol Hepatol. 2018;3(5):317-25. https://doi.org/10. 1016/S2468-1253(18)30029-3 (Epub 2018 Mar 2).

44. Kamal A, Elmoety AAA, Rostom YAM, Shater MS, Lashen SA. Percutaneous radiofrequency versus microwave ablation for management of hepatocellular carcinoma: a randomized controlled trial. J Gastrointest Oncol. 2019;10(3):562-71. https://doi.org/10.21037/jgo.2019.01.34.

45. Abdelaziz A, ElbazT, Shousha HI, Mahmoud S, Ibrahim M, Abdelmaksoud A, Nabeel M. Efficacy and survival analysis of percutaneous radiofrequency versus microwave ablation for hepatocellular carcinoma: an Egyptian multidisciplinary clinic experience. Surg Endosc. 2014;28(12):3429-34. https://doi.org/10.1007/s00464-014-3617-4 (Epub 2014 Jun 17)

46. Du S, Yang JZ, Chen J, Zhou WG, Sun YY. Comparisons of recurrencefree survival and overall survival between microwave versus radiofrequency ablation treatment for hepatocellular carcinoma: a multiple centers retrospective cohort study with propensity score matching. PLoS ONE. 2020;15(1): e0227242. https://doi.org/10.1371/journal.pone. 0227242.

47. Cillo U, Noaro G, Vitale A, Neri D, D’Amico F, Gringeri E, Farinati F, Vincenzi V, Vigo M, Zanus G, HePaTIC Study Group. Laparoscopic microwave ablation in patients with hepatocellular carcinoma: a prospective cohort study. HPB (Oxford). 2014;16(11):979-86. https://doi.org/10. 1111/hpb.12264 (Epub 2014 Apr 18).

48. Ghweil A, Osman H. Percutaneous microwave and radiofrequency ablation for hepatocellular carcinoma: a retrospective comparative study. Hepatol Int. 2019;13(1):1-266.

49. Zhang L, Wang N, Shen Q, Cheng W, Qian GJ. Therapeutic efficacy of percutaneous radiofrequency ablation versus microwave ablation for hepatocellular carcinoma. PLoS ONE. 2013;8(10): e76119. https://doi. org/10.1371/journal.pone.0076119.

50. Vogl TJ, Farshid P, Naguib NN, Zangos S, Bodelle B, Paul J, Mbalisike EC, Beeres M, Nour-Eldin NE. Ablation therapy of hepatocellular carcinoma: a comparative study between radiofrequency and microwave ablation. Abdom Imaging. 2015;40(6):1829-37. https://doi.org/10.1007/ s00261-015-0355-6.

51. Potretzke TA, Ziemlewicz TJ, Hinshaw JL, Lubner MG, Wells SA, Brace CL, Agarwal P, Lee FT Jr. Microwave versus radiofrequency ablation treatment for hepatocellular carcinoma: a comparison of efficacy at a single center. J Vasc Interv Radiol. 2016;27(5):631-8. https://doi.org/10.1016/j. jvir.2016.01.136 (Epub 2016 Mar 24).

52. Ding J, Jing $X$, Liu J, Wang Y, Wang F, Wang Y, Du Z. Comparison of two different thermal techniques for the treatment of hepatocellular carcinoma. Eur J Radiol. 2013;82(9):1379-84. https://doi.org/10.1016/j.ejrad. 2013.04.025 (Epub 2013 May 28).

53. Xu Y, Shen Q, Wang N, Wu PP, Huang B, Kuang M, Qian GJ. Microwave ablation is as effective as radiofrequency ablation for very-early-stage hepatocellular carcinoma. Chin J Cancer. 2017;36(1):14. https://doi.org/ 10.1186/s40880-017-0183-x. 
54. Santambrogio R, Chiang J, Barabino M, Meloni FM, Bertolini E, Melchiorre F, Opocher E. Comparison of laparoscopic microwave to radiofrequency ablation of small hepatocellular carcinoma $(\leq 3 \mathrm{~cm})$. Ann Surg Oncol. 2017;24(1):257-63. https://doi.org/10.1245/s10434-016-5527-2 (Epub 2016 Aug 31).

55. Feng K, Yan J, Li X, Xia F, Ma K, Wang S, Bie P, Dong J. A randomized controlled trial of radiofrequency ablation and surgical resection in the treatment of small hepatocellular carcinoma. J Hepatol. 2012;57(4):794802. https://doi.org/10.1016/j.jhep.2012.05.007 (Epub 2012 May 23).

56. Fang Y, Chen W, Liang X, Li D, Lou H, Chen R, Wang K, Pan H. Comparison of long-term effectiveness and complications of radiofrequency ablation with hepatectomy for small hepatocellular carcinoma. J Gastroenterol Hepatol. 2014;29(1):193-200. https://doi.org/10.1111/jgh. 12441.

57. Hung HH, Chiou YY, Hsia CY, Su CW, Chou YH, Chiang JH, Kao WY, Huo $\mathrm{Tl}$, Huang YH, Su YH, Lin HC, Lee SD, Wu JC. Survival rates are comparable after radiofrequency ablation or surgery in patients with small hepatocellular carcinomas. Clin Gastroenterol Hepatol. 2011;9(1):79-86. https://doi.org/10.1016/j.cgh.2010.08.018 (Epub 2010 Sep 8).

58. Wong KM, Yeh ML, Chuang SC, Wang LY, Lin ZY, Chen SC, Tsai JF, Wang SN, Kuo KK, Dai CY, Yu ML, Lee KT, Chuang WL. Survival comparison between surgical resection and percutaneous radiofrequency ablation for patients in Barcelona Clinic Liver Cancer early stage hepatocellular carcinoma. Indian J Gastroenterol. 2013;32(4):253-7. https://doi.org/10. 1007/s12664-012-0225-x (Epub 2012 Aug 30).

59. Wang JH, Wang CC, Hung CH, Chen CL, Lu SN. Survival comparison between surgical resection and radiofrequency ablation for patients in BCLC very early/early stage hepatocellular carcinoma. J Hepatol. 2012;56(2):412-8. https://doi.org/10.1016/j.jhep.2011.05.020 (Epub 2011 Jul 12).

60. Imai K, Beppu T, Chikamoto A, Doi K, Okabe H, Hayashi H, Nitta H, Ishiko T, Takamori H, Baba H. Comparison between hepatic resection and radiofrequency ablation as first-line treatment for solitary small-sized hepatocellular carcinoma of $3 \mathrm{~cm}$ or less. Hepatol Res. 2013;43(8):85364. https://doi.org/10.1111/hepr.12035 (Epub 2013 Jan 2).

61. Yang HJ, Lee JH, Lee DH, Yu SJ, Kim YJ, Yoon JH, Kim HC, Lee JM, Chung JW, Yi NJ, Lee KW, Suh KS, Lee HS. Small single-nodule hepatocellular carcinoma: comparison of transarterial chemoembolization, radiofrequency ablation, and hepatic resection by using inverse probability weighting. Radiology. 2014;271(3):909-18. https://doi.org/10.1148/ radiol.13131760 (Epub 2014 Feb 8).

62. Hocquelet A, Balageas P, Laurent C, Blanc JF, Frulio N, Salut C, Cassinotto C, Saric J, Possenti L, Bernard PH, Montaudon M, Trillaud H. Radiofrequency ablation versus surgical resection for hepatocellular carcinoma within the Milan criteria: a study of 281 Western patients. Int J Hyperthermia. 2015;31(7):749-57. https://doi.org/10.3109/02656736.2015. 1068382 (Epub 2015 Sep 12)

63. Liu PH, Hsu CY, Hsia CY, Lee YH, Huang YH, Chiou YY, Lin HC, Huo TI. Surgical resection versus radiofrequency ablation for single hepatocellular carcinoma $\leq 2 \mathrm{~cm}$ in a propensity score model. Ann Surg. 2016;263(3):538-45. https://doi.org/10.1097/SLA.00000000000001178 (Erratum.In:AnnSurg.2016May;263(5):e77).

64. Guan TP, Fang CH, Yang J, Xiang N, Chen QS, Zhong SZ. A Comparison between three-dimensional visualization guided hepatectomy and ultrasonography guided radiofrequency ablation in the treatment of small hepatocellular carcinoma within the milan criteria. Biomed Res Int. 2016;2016:8931732. https://doi.org/10.1155/2016/8931732 (Epub 2016 May 12. Retraction in: Biomed Res Int. 2017;2017:8014852)

65. Ng KKC, Chok KSH, Chan ACY, Cheung TT, Wong TCL, Fung JYY, Yuen J, Poon RTP, Fan ST, Lo CM. Randomized clinical trial of hepatic resection versus radiofrequency ablation for early-stage hepatocellular carcinoma. Br J Surg. 2017;104(13):1775-84. https://doi.org/10.1002/bjs. 10677 (Epub 2017 Nov 1).

66. Lee HW, Lee JM, Yoon JH, Kim YJ, Park JW, Park SJ, Kim SH, Yi NJ, Suh KS. A prospective randomized study comparing radiofrequency ablation and hepatic resection for hepatocellular carcinoma. Ann Surg Treat Res. 2018;94(2):74-82. https://doi.org/10.4174/astr.2018.94.2.74 (Epub 2018 Jan 30).

67. Santambrogio R, Bruno S, Kluger MD, Costa M, Salceda J, Belli A, Laurent A, Barabino M, Opocher E, Azoulay D, Cherqui D. Laparoscopic ablation therapies or hepatic resection in cirrhotic patients with small hepatocellular carcinoma. Dig Liver Dis. 2016;48(2):189-96. https://doi. org/10.1016/j.dld.2015.11.010 (Epub 2015 Nov 23).

68. Oh JH, Sinn DH, Choi GS, Kim JM, Joh JW, Kang TW, Hyun D, Kang W, Gwak GY, Paik YH, Lee JH, Koh KC, Paik SW, Choi MS. Comparison of outcome between liver resection, radiofrequency ablation, and transarterial therapy for multiple small hepatocellular carcinoma within the Milan criteria. Ann Surg Treat Res. 2020;99(4):238-46. https://doi.org/10. 4174/astr.2020.99.4.238 (Epub 2020 Sep 24).

69. Hsiao CY, Hu RH, Ho CM, Wu YM, Lee PH, Ho MC. Surgical resection versus radiofrequency ablation for Barcelona Clinic Liver Cancer very early stage hepatocellular carcinoma: long-term results of a single-center study. Am J Surg. 2020;220(4):958-64. https://doi.org/10.1016/j.amjsurg. 2020.03.017 (Epub 2020 Mar 25).

70. Liang B, Yao S, Zhou J, Li Z, Liu T. Liver resection versus radiofrequency ablation for hepatitis B virus-related small hepatocellular carcinoma. J Hepatocell Carcinoma. 2018;12(5):1-7. https://doi.org/10.2147/JHC. S152202.

71. Di Sandro S, Benuzzi L, Lauterio A, Botta F, De Carlis R, Najjar M, Centonze L, Danieli M, Pezzoli I, Rampoldi A, Bagnardi V, De Carlis L. Single Hepatocellular Carcinoma approached by curative-intent treatment: a propensity score analysis comparing radiofrequency ablation and liver resection. Eur J Surg Oncol. 2019;45(9):1691-9. https://doi.org/10. 1016/j.ejso.2019.04.023 (Epub 2019 Apr 29).

72. Santambrogio R, Barabino M, Bruno S, Mariani N, Maroni N, Bertolini E, Franceschelli G, Opocher E. Surgical resection vs. ablative therapies through a laparoscopic approach for hepatocellular carcinoma: a comparative study. J Gastrointest Surg. 2018;22(4):650-60. https://doi. org/10.1007/s11605-017-3648-y (Epub 2017 Dec 12).

73. Casaccia M, Santori G, Bottino G, Diviacco P, Andorno E. Laparoscopic resection vs laparoscopic radiofrequency ablation for the treatment of small hepatocellular carcinomas: a single-center analysis. World J Gastroenterol. 2017;23(4):653-60. https://doi.org/10.3748/wjg.v23.i4. 653.

74. Song J, Wang Y, Ma K, Zheng S, Bie P, Xia F, Li X, Li J, Wang X, Chen J. Laparoscopic hepatectomy versus radiofrequency ablation for minimally invasive treatment of single, small hepatocellular carcinomas. Surg Endosc. 2016;30(10):4249-57. https://doi.org/10.1007/s00464-0154737-1 (Epub 2015 Dec 29).

75. Vitali GC, Laurent A, Terraz S, Majno P, Buchs NC, Rubbia-Brandt L, Luciani A, Calderaro J, Morel P, Azoulay D, Toso C. Minimally invasive surgery versus percutaneous radio frequency ablation for the treatment of single small $(\leq 3 \mathrm{~cm})$ hepatocellular carcinoma: a case-control study. Surg Endosc. 2016;30(6):2301-7. https://doi.org/10.1007/s00464-0154295-6 (Epub 2015 Nov 3).

76. Ogiso S, Seo S, Eso Y, Yoh T, Kawai T, Okumura S, Ishii T, Fukumitsu K, Taura K, Seno H, Uemoto S. Laparoscopic liver resection versus percutaneous radiofrequency ablation for small hepatocellular carcinoma. HPB (Oxford). 2021;23(4):533-7. https://doi.org/10.1016/j.hpb.2020.08.009 (Epub 2020 Sep 7)

77. Chong CC, Lee KF, Chu CM, Chan AW, Yu SC, Lai PB. Laparoscopic hepatectomy (with or without robotic assistance) versus radiofrequency ablation as a minimally invasive treatment for very early-stage or earlystage hepatocellular carcinoma. Dig Surg. 2020;37(1):65-71. https://doi. org/10.1159/000497112 (Epub 2019 Mar 27).

78. Wahl DR, Stenmark MH, Tao Y, Pollom EL, Caoili EM, Lawrence TS, Schipper MJ, Feng M. Outcomes after stereotactic body radiotherapy or radiofrequency ablation for hepatocellular carcinoma. J Clin Oncol. 2016;34(5):452-9. https://doi.org/10.1200/JCO.2015.61.4925 (Epub 2015 Nov 30).

79. Kim N, Kim HJ, Won JY, Kim DY, Han KH, Jung I, Seong J. Retrospective analysis of stereotactic body radiation therapy efficacy over radiofrequency ablation for hepatocellular carcinoma. Radiother Oncol. 2019;131:81-7. https://doi.org/10.1016/j.radonc.2018.12.013 (Epub 2018 Dec 31).

80. Sun J, Wang Q, Hong ZX, Li WG, He WP, Zhang T, Zhang AM, Fan YZ, Sun $Y Z$, Zheng L, Duan $X Z$. Stereotactic body radiotherapy versus hepatic resection for hepatocellular carcinoma $(\leq 5 \mathrm{~cm})$ : a propensity score analysis. Hepatol Int. 2020;14(5):788-97. https://doi.org/10.1007/ s12072-020-10088-0 (Epub 2020 Sep 4).

81. Nakano R, Ohira M, Kobayashi T, Ide K, Tahara H, Kuroda S, Shimizu S, Kimura T, Nagata Y, Aikata H, Chayama K, Ohdan H. Hepatectomy versus 
stereotactic body radiotherapy for primary early hepatocellular carcinoma: a propensity-matched analysis in a single institution. Surgery. 2018;164(2):219-26. https://doi.org/10.1016/j.surg.2018.03.006 (Epub 2018 May 23).

82. Martin AN, Wilkins LR, Das D, Johnston LE, Bauer TW, Adams RB, Zaydfudim VM. Efficacy of radiofrequency ablation versus transarterial chemoembolization for patients with solitary hepatocellular carcinoma $\leq 3 \mathrm{~cm}$. Am Surg. 2019;85(2):150-5

83. Wang C, Wang H, Yang W, Hu K, Xie H, Hu KQ, Bai W, Dong Z, Lu Y, Zeng Z, Lou M, Wang H, Gao X, Chang X, An L, Qu J, Li J, Yang Y. Multicenter randomized controlled trial of percutaneous cryoablation versus radiofrequency ablation in hepatocellular carcinoma. Hepatology. 2015;61(5):1579-90. https://doi.org/10.1002/hep.27548 (Epub 2015 Mar 20).

84. Xu J, Noda C, Erickson A, Mokkarala M, Charalel R, Ramaswamy R, Tao YU, Akinwande O. Radiofrequency ablation vs. cryoablation for localized hepatocellular carcinoma: a propensity-matched population study. Anticancer Res. 2018;38(11):6381-6. https://doi.org/10.21873/anticanres. 12997.

85. Hu J, Chen S, Wang X, Lin N, Yang J, Wu S. Image-guided percutaneous microwave ablation versus cryoablation for hepatocellular carcinoma in high-risk locations: intermediate-term results. Cancer Manag Res. 2019;18(11):9801-11. https://doi.org/10.2147/CMAR.S227961.

86. Burdorf A, van der Beek AJ. To RCT or not to RCT: evidence on effectiveness of return-to-work interventions. Scand J Work Environ Health. 2016:42(4):257-9. https://doi.org/10.5271/sjweh.3577 (Epub 2016 Jun 7).

87. Tsoris A, Marlar CA. Use of the child pugh score in liver disease. In: StatPearls [Internet]. Treasure Island (FL): StatPearls Publishing; 2021

88. Mokdad AA, Singal AG, Marrero JA, Zhu H, Yopp AC. Vascular invasion and metastasis is predictive of outcome in barcelona clinic liver cancer stage C hepatocellular carcinoma. J Natl Compr Canc Netw. 2017;15(2):197-204. https://doi.org/10.6004/jnccn.2017.0020.

89. Garuti F, Neri A, Avanzato F, Gramenzi A, Rampoldi D, Rucci P, Farinati F, Giannini EG, Piscaglia F, Rapaccini GL, Di Marco M, Caturelli E, Zoli M, Sacco R, Cabibbo G, Marra F, Mega A, Morisco F, Gasbarrini A, Svegliati-Baroni G, Foschi FG, Missale G, Masotto A, Nardone G, Raimondo G, Azzaroli F, Vidili G, Brunetto MR, Trevisani F, ITA.LI.CA study group. The changing scenario of hepatocellular carcinoma in Italy: an update. Liver Int. 2021;41(3):58597. https://doi.org/10.1111/liv.14735 (Epub 2020 Dec 2).

90. Tsochatzis E, Meyer T, O'Beirne J, Burroughs AK. Transarterial chemoembolisation is not superior to embolisation alone: the recent European Association for the Study of the Liver (EASL) —European Organisation for Research and Treatment of Cancer (EORTC) guidelines. Eur J Cancer. 2013;49(6):1509-10. https://doi.org/10.1016/j.ejca.2012.11.012 (Epub 2012 Dec 8).

91. Kaibori M, Yoshii K, Hasegawa K, Ariizumi S, Kobayashi T, Kamiyama T, Kudo A, Yamaue H, Kokudo N, Yamamoto M. Impact of systematic segmentectomy for small hepatocellular carcinoma. J Hepatobiliary Pancreat Sci. 2020;27(6):331-41. https://doi.org/10.1002/jhbp.720 (Epub 2020 Feb 27).

92. Zhu GQ, Sun M, Liao WT, Yu WH, Zhou SL, Zhou ZJ, Shi YH, Fan J, Zhou J, Qiu LX, Dai Z. Comparative efficacy and safety between ablative therapies or surgery for small hepatocellular carcinoma: a network meta-analysis. Expert Rev Gastroenterol Hepatol. 2018;12(9):935-45. https://doi.org/10. 1080/17474124.2018.1503531 (Epub 2018 Jul 25).

93. Ricci AD, Rizzo A, Bonucci C, Tavolari S, Palloni A, Frega G, Mollica V, Tober N, Mazzotta E, Felicani C, Serra C, Brandi G. The (Eternal) debate on microwave ablation versus radiofrequency ablation in BCLC-A hepatocellular carcinoma. In Vivo. 2020;34(6):3421-9. https://doi.org/10.21873/invivo. 12181.

94. Gui CH, Baey S, D'cruz RT, Shelat VG. Trans-arterial chemoembolization + radiofrequency ablation versus surgical resection in hepatocellular carcinoma-a meta-analysis. Eur J Surg Oncol. 2020;46(5):763-71. https:// doi.org/10.1016/j.ejso.2020.01.004 (Epub 2020 Jan 7).

95. Zhou Y, Zhao Y, Li B, Xu D, Yin Z, Xie F, Yang J. Meta-analysis of radiofrequency ablation versus hepatic resection for small hepatocellular carcinoma. BMC Gastroenterol. 2010;9(10):78. https://doi.org/10.1186/1471-230X-10-78.

96. Liu Z, ZhouY, Zhang P, Qin H. Meta-analysis of the therapeutic effect of hepatectomy versus radiofrequency ablation for the treatment of hepatocellular carcinoma. Surg Laparosc Endosc Percutan Tech. 2010;20(3):130-40. https://doi.org/10.1097/SLE.0b013e3181d823df.
97. Rizzo A, Frega G, Ricci AD, Palloni A, Abbati F, De Lorenzo S, Deserti M, Tavolari S, Brandi G. Anti-EGFR monoclonal antibodies in advanced biliary tract cancer: a systematic review and meta-analysis. In Vivo. 2020;34(2):479-88. https://doi.org/10.21873/invivo.11798.

98. Lee DH, Lee JM. Recent advances in the image-guided tumor ablation of liver malignancies: radiofrequency ablation with multiple electrodes, real-time multimodality fusion imaging, and new energy sources. Korean J Radiol. 2018;19(4):545-59. https://doi.org/10.3348/kjr.2018.19.4.545 (Epub 2018 Jun 14)

99. Imajo K, Ogawa Y, Yoneda M, Saito S, Nakajima A. A review of conventional and newer generation microwave ablation systems for hepatocellular carcinoma. J Med Ultrason (2001). 2020;47(2):265-77. https://doi.org/10. 1007/s10396-019-00997-5 (Epub 2020 Jan 20).

100. Patel HR. Effects of cross diffusion and heat generation on mixed convective MHD flow of Casson fluid through porous medium with non-linear thermal radiation. Heliyon. 2019;5(4): e01555. https://doi.org/10.1016/j.heliyon. 2019.e01555.

101. Sparchez Z, Mocan T, Radu P, Mocan LP, Sparchez M, Leucuta DC, Al HN. Prognostic factors after percutaneous radiofrequency ablation in the treatment of hepatocellular. Carcinoma impact of incomplete ablation on recurrence and overall survival rates. J Gastrointestin Liver Dis. 2018;27(4):399-407. https://doi.org/10.15403/jgld.2014.1121.274.pro.

102. Facciorusso A, AbdElAziz MA, Tartaglia N, Ramai D, Mohan BP, Cotsoglou C, Pusceddu S, Giacomelli L, Ambrosi A, Sacco R. Microwave ablation versus radiofrequency ablation for treatment of hepatocellular carcinoma: a meta-analysis of randomized controlled trials. Cancers (Basel). 2020;12(12):3796. https://doi.org/10.3390/cancers12123796.

103. Tan W, Deng Q, Lin S, Wang Y, Xu G. Comparison of microwave ablation and radiofrequency ablation for hepatocellular carcinoma: a systematic review and meta-analysis. Int J Hyperthermia. 2019;36(1):264-72. https://doi.org/ 10.1080/02656736.2018.1562571 (Epub 2019 Jan 24).

104. Kalra N, Gupta P, Jugpal T, Naik SS, Gorsi U, Chaluvashetty SB, Bhujade H, Duseja A, Singh V, Dhiman RK, Sandhu MS. Percutaneous cryoablation of liver tumors: initial experience from a tertiary care center in India. J Clin Exp Hepatol. 2021;11(3):305-11. https://doi.org/10.1016/j.jceh.2020.10.005 (Epub 2020 Oct 19).

105. Lin Y, Wen Q, Guo L, Wang H, Sui G, Sun Z. A network meta-analysis on the efficacy and prognosis of different interventional therapies for early-stage hepatocellular carcinoma. Int J Hyperthermia. 2018;35(1):450-62. https:// doi.org/10.1080/02656736.2018.1507047 (Epub 2018 Oct 25).

106. Lan T, Chang L, Mn R, Wu L, Yuan YF. Comparative efficacy of interventional therapies for early-stage hepatocellular carcinoma: a PRISMA-compliant systematic review and network meta-analysis. Medicine (Baltimore). 2016;95(15): e3185. https://doi.org/10.1097/MD.0000000000003185.

107. Wang H, Jin C, Fang L, Sun H, Cheng W, Hu S. Health economic evaluation of stereotactic body radiotherapy (SBRT) for hepatocellular carcinoma: a systematic review. Cost Eff Resour Alloc. 2020;10(18):1. https://doi.org/10. 1186/s12962-019-0198-Z.

108. Rim CH, Yoon WS. Leaflet manual of external beam radiation therapy for hepatocellular carcinoma: a review of the indications, evidences, and clinical trials. Onco Targets Ther. 2018;16(11):2865-74. https://doi.org/10.2147/ OTT.S164651.

109. Sanuki N,Takeda A.Arehead-to-head comparisons between radiofrequency ablation and stereotactic body radiotherapy really necessary for localized hepatocellular carcinoma? J Clin Oncol. 2018;36(24):2563-4. https://doi. org/10.1200/JCO.2018.78.2805 (Epub 2018 Jun 26).

110. Qi X, Tang Y, An D, Bai M, Shi X, Wang J, Han G, Fan D. Radiofrequency ablation versus hepatic resection for small hepatocellular carcinoma: a meta-analysis of randomized controlled trials. J Clin Gastroenterol. 2014;48(5):450-7. https://doi.org/10.1097/MCG.0000000000000008.

111. Tierney JF, Stewart LA, Ghersi D, Burdett S, Sydes MR. Practical methods for incorporating summary time-to-event data into meta-analysis. Trials. 2007;7(8):16. https://doi.org/10.1186/1745-6215-8-16.

112. Shrier I, Boivin JF, Steele RJ, Platt RW, Furlan A, Kakuma R, Brophy J, Rossignol $M$. Should meta-analyses of interventions include observational studies in addition to randomized controlled trials? A critical examination of underlying principles. Am J Epidemiol. 2007;166(10):1203-9. https://doi.org/10. 1093/aje/kwm189; (Epub 2007 Aug 21). 


\section{Publisher's Note}

Springer Nature remains neutral with regard to jurisdictional claims in published maps and institutional affiliations. 